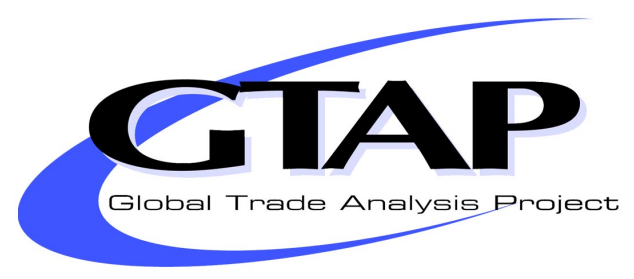

\title{
Theoretical Structure of Dynamic GTAP
}

\author{
Elena Ianchovichina and Robert McDougall
}

GTAP Technical Paper No. 17

December 2000

Elena Ianchovichina: Development Research Group, The World Bank, 1818 H Street NW, Washington, DC 20433, USA.

Robert McDougall: Deputy Director, Center for Global Trade Analysis, Department of Agricultural Economics, Purdue University, 1145 Krannert Building, West Lafayette, IN 47907 


\title{
Theoretical Structure of Dynamic GTAP
}

\author{
Elena Ianchovichina and Robert McDougall*
}

GTAP Technical Paper No. 17

December, 2000

\begin{abstract}
This paper documents the foreign asset ownership and investment theory of the dynamic GTAP model (GTAP-Dyn). The new investment theory offers a disequilibrium approach to modeling endogenously international capital mobility. It permits a recursive solution procedure, a feature that allows easy implementation of dynamics into any static AGE model without imposing limitations on the model's size. The method involves treating time as a variable, not as an index. Having time as a variable allows the construction of dynamic GTAP with minimum modification to the existing structure of GTAP, by separating the theory of static GTAP from the length of run.
\end{abstract}

JEL classifications: D58

Key words: Dynamics, asset ownership, international capital mobility, investment, adaptive expectations

*Ianchovichina: Development Research Group, The World Bank, 1818 H Street NW, Washington, DC 20433, USA. McDougall, Center for Global Trade Analysis, Department of Agricultural Economics, Purdue University, 1145 Krannert Building, IN 47907, USA. We thank Philip Adams, Kevin Hanslow, Ken Pearson, and Terrie Walmsley for helpful comments on earlier drafts of this paper. 


\section{Contents}

1 Introduction 1

2 Time 3

2.1 The discrete-time approach . . . . . . . . . . . . . 3

2.2 The continuous-time approach .................. 6

3 Capital accumulation $\quad 8$

4 Financial assets and associated income flows $\quad 9$

4.1 General features . . . . . . . . . . . . . . . . . . . . . . 9 9

4.2 Notation . . . . . . . . . . . . . . . . . . . . 12

4.3 Asset accumulation . . . . . . . . . . . . . . . . . . . 13

4.4 Assets and liabilities of firms and households . . . . . . . . . . . . 15

4.5 Assets and liabilities of the global trust . . . . . . . . . . . . . . 22

4.6 Income from financial assets . . . . . . . . . . . . . . . . . . . . . 24

5 Investment Theory $\quad \mathbf{2 7}$

5.1 The required rate of growth in the rate of return $\ldots \ldots . . \ldots 27$

5.2 The expected rate of growth in the rate of return . . . . . . . . . . 31

5.3 Adaptive expectations . . . . . . . . . . . . . . . . . . 34

5.4 The normal rate of growth in the capital stock . . . . . . . . . . . . 39

5.5 Summary . . . . . . . . . . . . . . . . . . . 41

5.6 Alternative investment determination . . . . . . . . . . . . . 43

6 Properties and problems $\quad 44$

6.1 Long-run equilibrium . . . . . . . . . . . . . . . . . . . . . . 44

6.2 Cumulative and comparative dynamic results . . . . . . . . . . . . . 46

6.3 Path dependence . . . . . . . . . . . . . . . . . . . . 47

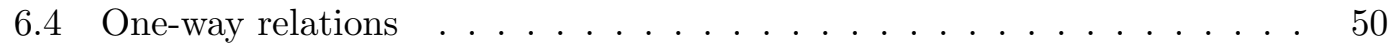

6.5 Capital account volatility and the propensity to save . . . . . . . . . 51

7 Concluding remarks

8 References $\quad 52$

$\begin{array}{ll}\text { A Tables } & 54\end{array}$

B Figures $\quad 55$

$\begin{array}{ll}\text { C Nomenclature } & 61\end{array}$ 


\section{Introduction}

GTAP-Dyn is a recursively dynamic applied general equilibrium ( $A G E$ ) model of the world economy. It extends the standard GTAP model (Hertel, 1997) to include international capital mobility, capital accumulation, and an adaptive expectations theory of investment. This paper documents the extended theoretical structure.

Standard GTAP (Hertel and Tsigas, 1997) is a comparative-static AGE model of the world economy, developed as a vehicle for teaching multi-country AGE modeling and to complement the GTAP multi-country AGE data base (Gehlhar, Gray, Hertel et al., 1997). In general, it aims to provide a straightforward presentation of widely used AGE modeling techniques. It does however include some special features, notably an extensive decomposition of welfare results.

The main objective of GTAP-Dyn is to provide a better treatment of the long run within the GTAP framework. In standard GTAP, capital can move between industries within a region, but not between regions. This impedes analysis of policy shocks and other developments diversely affecting incentives to invest in different regions. For a good long run treatment, then, we need international capital mobility.

With capital mobile between regions, we need to expand the national accounts to allow for international income payments. Policies that attract capital to a region may have a strong impact on gross domestic product; but, if the investment is funded from abroad, the impact on gross national product and national income may be much weaker. So, to avoid creating spurious links between investment and welfare, we need to distinguish between asset ownership and asset location: the assets owned by a region need no longer be the assets located in the region; the income generated by the assets in a region need no longer accrue to that region's residents.

To distinguish between asset location and ownership, we introduce a rudimentary representation of financial assets. Regions now accumulate not only physical capital stocks but also claims to the ownership of physical capital. These ownership claims are financial assets of some kind. Thus international income receipts and payments emerge as part of the system of accounting for financial assets.

With capital internationally mobile, we need to determine regional capital stocks. This is most satisfactorily done in a dynamic model. First, tracing out the investment and capital stock time paths is the best way to assure ourselves that the endof-simulation capital stocks are reasonable. Second, the immediate impact of the earlier-period investments required to achieve the end-of-simulation stocks on regional economies is itself of some interest. Accordingly, we make the model dynamic, and incorporate the stock-flow or intrinsic dynamics of investment and capital accumulation. 
Likewise, we incorporate the intrinsic dynamics of saving and wealth accumulation.

Accordingly, the key features of this extension are endogenous regional capital stocks, international assets and liabilities and international investment and income flows, financial assets, and intrinsic dynamics of physical and financial asset stocks. While introducing these new features we seek to preserve the strengths of the standard model, including the ability to work with empirical rather than highly stylized data bases, the ability to solve in reasonable time on reasonable computing platforms while preserving a detailed regional and sectoral disaggregation, and a money metric of utility and an associated decomposition.

The resultant model should be suitable for medium- and long-run policy analysis, in which the comparative statics of the end-of-simulation solution is supplemented with time paths leading to the solutions. It has enough dynamics and a sufficient treatment of financial assets to support this, but not enough to support short-run macroeconomic dynamics or financial or monetary economics.

This paper documents the theoretical structure of GTAP-Dyn as implemented in the solution program. While we motivate each significant design decision, we do not provide a tutorial introduction to the model, nor an academic treatment grounding the model in the previous literature, but a technical reference. We intend to maintain this document synchronously with the solution program, so that each revision of the standard GTAP-Dyn solution program is accompanied by a corresponding revision of this paper. This should ensure that a basic minimum level of documentation for the theoretical structure is always available.

A salient technical feature of the new extension is the treatment of time. Many dynamic models treat time as an index, so that each variable in the model has a time index. In GTAP-Dyn, time itself is a variable, subject to exogenous change along with the usual policy, technology, and demographic variables. Section 2 elucidates the mechanics and motivation of this treatment, and section 3 applies it to the capital accumulation equation. This lays the groundwork for the discussion in section 4 of wealth accumulation, financial asset determination, and foreign income flows. Section 5 describes the investment theory, incorporating lagged adjustment of capital stocks and adaptive expectations for the rate of return. Section 6 discusses the properties of the complete model, the existence of and convergence toward a long-run equilibrium. The paper concludes in section 7 with a summary of the strengths and limitations of the new approach.

We provide a number of aids to the reader, to assist in following the notation and in relating the paper to the solution program source code. We mark the definitions of coefficients and variables by inserting their name as a marginal note. We provide a de- 
scriptive listing of coefficients and variables appearing in the model code in appendix C. We give each equation appearing in the model in two or three forms: the levels equation, if appropriate, in mathematical notation, the differential (change) equation, in mathematical notation, and the differential equation, as coded in the model. The coded equations are close but not literal transcriptions from the source code; since the layout of the source code is still subject to revision, literal transcriptions are undesirable at this time.

\section{Time}

As noted above (section 1), a key technical feature of GTAP-Dyn is the treatment of time not as a discrete index but as a continuous variable. Since however the continuous time treatment may be less familiar to many readers, we first overview the more familiar discrete time approach, and then contrast the two. Within the vary large class of dynamic economic models, we confine our discussion to recursively solvable CGE models. In discussing solution methods, we assume the use of the GEMPACK suite of economic modeling software.

We use a simplified wealth accumulation equation to illustrate and contrast the two approaches. This equation combines features that might be separated between the capital and wealth accumulation equations in a more complex model. It may not correspond exactly to any accumulation equation in any working model, but it does, we believe, support a fair presentation of features and issues typically encountered in such models.

We consider a closed economy with a single capital good, which constitutes the sole economic asset and hence the sole vehicle for saving. Real wealth may then be defined as the size $K$ of the capital stock. The evolution of the capital stock through time is given by an integral equation,

$$
K=K_{0}+\int_{T_{0}}^{T} I(\tau) d \tau
$$

where $K_{0}$ denotes the capital stock at some base time $T_{0}$, and $I$, net investment.

\subsection{The discrete-time approach}

Within a recursively solvable discrete-time framework, there is typically a concept of a time period. A given data base refers to a given time period; a simulation takes the data base to the next time period, with simulation results representing changes between 
the initial period and the next.

Within such a framework, the database might include a representation of the economy in the current period, together with some extra data pertaining to the next period. The representation of the economy might contain values as of the start of the period, or as of the midpoint of the period, or average values over the period. The extra data might be just the period length, or might include for example values of stocks at the start of the next period.

Suppose that the data base contains a representation of the economy at the start of the period, together with the period length. We have from equation (1), by the mean value theorem, assuming a continuous time path for investment $I$,

$$
K=K_{0}+\left(T-T_{0}\right) I\left(T_{m}\right)
$$

for some $T_{m}$ between $T_{0}$ and $T$, where we now interpret the base time $T_{0}$ as the start of the period represented by the initial data base. For small $T-T_{0}$, we have $I\left(T_{m}\right) \approx I\left(T_{0}\right)$, so

$$
K \approx K_{0}+I_{0} L
$$

where $L$ denotes the interval length $T-T_{0}$. Differentiating, we obtain the percentage change in the capital stock $k$ within the simulation,

$$
k \approx 100 \frac{I_{0} L}{K_{0}}
$$

We may calculate the right hand side as a formula outside the model, and apply it as a shock to $k$; or, to avoid performing a separate calculation before the simulation, we may include a capital accumulation equation within the solution program, writing

$$
k \approx 100 \frac{I_{0} L}{K_{0}} h
$$

where $h$ is an artificial variable (sometimes called a homotopy variable) that is always exogenous and always receives a shock of 1 in a dynamic simulation. Note that the coefficients $I_{0}$ and $K_{0}$ refer to the start-of-simulation data base and are not updated within the simulation.

We note that the change equation, equation (3), is true only approximately, not exactly. This is not because of linearization error arising in the passage from the levels to the change equation: indeed, there is no such error, since the levels equation, equation (2), is itself linear. Instead, the change equation inherits error from the levels equation, since the levels equation is itself inexact. Since the error is inherent in the 
levels equation, it cannot be reduced by refinements in the solution procedure, such as using smaller step sizes. The only way to reduce it is by revising the simulation strategy, using more simulations with shorter time intervals. Once the time interval is set, we have an irreducible inaccuracy in the accumulation equation.

At this point, readers familiar with the discrete time approach may object that their own favorite discrete-time model does not suffer from this particular inaccuracy. In general, however, it appears that it is possible to change the form of the inaccuracy, but not to eliminate it. Suppose for example that the data base represents the average state of the economy through the period, together with start-of-period and end-ofperiod stocks. Then we can derive exact equations for the start-of-period and endof-period stocks for the next period, given initial-period and next-period investment. To calculate the next-period average capital stock value, however, we need to know how investment is distributed in time through the next period; but we cannot know this. So the determination of the through-period-average capital stock is necessarily approximate.

For sufficiently small time steps, this inaccuracy does not matter much; for larger time steps, we must replace equation (3) by some other (more complex) equation that offers a better approximation over longer periods. For example, in our closed economy we may equate investment with saving; then we have $I=S / \Pi$, where $S$ denotes nominal net saving, and $\Pi$ the price of investment goods. Then writing $S_{A P}$ for the average propensity to save, we have $S=S_{A P} Y$ and $I=S_{A P} Y / \Pi$, where $Y$ denotes nominal income; then writing $Y$ as the product of real income $Y_{R}$ and some price index $P_{Y}$, we have

$$
I=\frac{S_{A P} P_{Y} Y_{R}}{\Pi}
$$

Substituting into equation (1), we have

$$
K=K_{0}+\int_{T_{0}}^{T} \frac{S_{A P}(\tau) P_{Y}(\tau) Y_{R}(\tau)}{\Pi(\tau)} d \tau
$$

Now it is possible to solve equation (4) in terms of initial and final values of the variables under the integral, only with the aid of various supplementary assumptions. For example, one might assume that real income $Y_{R}$ maintains some constant growth rate between one period and the next; that the average propensity to consume, $S_{A P}$, maintains some constant time rate of change; and that the prices $P_{Y}$ and $\Pi$ jump immediately to their final values (prices being liable to overshooting, we might prefer this to a steady growth assumption). The resulting equation would obviously be quite different from (and far more complex than) equation (3). Less obviously, it will, like 
that equation, include period-length-dependent parameters.

Thus by making assumptions about time paths of variables between adjacent periods, we might derive a longer-run wealth accumulation equation. The details of the assumptions are not important; the point is that to implement the discrete-time approach for longer time intervals, we would need to make strong assumptions about the time paths of various economic variables between time periods; that the variables involved are typically endogenous to the system; and that the assumptions must be applied not at run time but in developing the accumulation equation.

The method we have outlined is just one of many ways to implement a discrete time treatment of capital accumulation, but it serves to illustrate some common features:

- The data base represents the economy in some period of time, possibly but not necessarily at a single time point within the period.

- The capital accumulation equation includes coefficients derived not from the current but from the start-of-simulation data base (it may also include some current coefficients, though in our illustrative example it does not).

- The capital accumulation equation includes parameters that depend on the size of the time step for the simulation (in our illustration, the time step size itself, $L)$.

- Given the size of the time step, there is some inaccuracy built into each experiment that cannot be removed by refining the solution procedure.

- Major changes in the step size are liable to require revision not only of the parameters but also of the form of the capital accumulation equation.

- For longer time intervals, the accumulation equations are liable to embody strong assumptions about time paths of endogenous variables.

In conclusion, the discrete time treatment of capital accumulation is perfectly viable, but it is apt to suffer from some minor problems including inaccuracy, special assumptions about investment paths, and inflexibility in the size of the time step. Fortunately, there is an alternative; capital accumulation lends itself naturally to a continuous time approach, as we now describe.

\subsection{The continuous-time approach}

Returning to equation (1), we now reinterpret the data base as representing the economy at some point in time. Both stock data and flow data refer to the same time point. 
Also we treat $T$ not as a discrete index but as a variable within the model. Totally differentiating then, we obtain the equation

$$
K=100 \frac{I}{K} t
$$

where $k$ represents percentage change in the capital stock, and $t$, change in time. This is very similar in form to the discrete-time equation (3). There are, however, two differences: the time variable $t$ replaces the homotopy variable $h$, and the equation uses the current rather than initial values of investment $I$ and the capital stock $K$.

These differences have major consequences. First, the new equation, being the linearized form of equation (1), involves a linearization error, but not an irreducible error. Thus the error in the calculation of the capital stock may be made as small as desired by refining the solution procedure, for example, by increasing the number of subintervals. Second, since there is no irreducible error, the equation is equally valid for any time interval. Third, since the length of the time interval is given by a variable $(t)$ rather than by a parameter $(L)$, the time interval length is determined at run time rather than in the data base.

In contrast then to the discrete-time approach, our approach:

- uses the data base to represent the economy at a point in time,

- in a multi-step solution, uses no coefficients derived from the start-of-simulation data base, but only current values,

- involves no parameters that depend on the length of the time interval,

- involves no irreducible inaccuracies in dynamic relations,

- uses the same accumulation equation for any time interval, and

- relies on no prior assumptions about the time paths of endogenous variables.

The notion of time as a variable can be explained in terms of the sources of change in an economy. An economy may change not only in response to changes in external circumstances such as technology, policy, or endowments, but also through the intrinsic dynamics of its stock-flow relationships. In the presence of non-zero net investment or saving, the passage of time leads to change in the stock of capital goods or of wealth. Furthermore, with adaptive expectations or lagged adjustment, the passage of time leads to the revision of expectations or the adjustment of target variables toward equilibrium. Such changes, arising not from changes in external circumstances but 
autonomously through the passage of time, we capture in time terms (terms in the time variable $t$ ) in the equation system. The shock to $t$ defines the change in time through the simulation; shocks to other exogenous variables represent accompanying changes in external circumstances.

\section{Capital accumulation}

We now begin to apply the time treatment described in section 2 to the GTAP-Dyn equation system. We begin with the capital accumulation equation, deriving the capital stock variable used both in the investment theory (section 5) and in the financial assets theory (section 4).

We begin with the integral equation for the capital stock,

$$
Q K=Q K_{-} O+\int_{\text {TIME_o }}^{T I M E} Q C G D S N E T d \tau
$$

where $Q K(r)$ represents the capital stock in region $r, Q K_{-} O(r)$ the capital stock at some base time TIME_O, TIME, current time, and QCGDSNET(r), net investment. Totally differentiating, we obtain

$$
Q K(r) \frac{q k(r)}{100}=Q C G D S N E T(r) . \text { time }
$$

where $q k(r)$ represents percentage change in the capital stock in region $r$, and time,

change in time. Multiplying both sides by one hundred times the price of capital goods, $q k$ we obtain

$$
V K(r) \cdot q k(r)=100 \operatorname{NETINV}(r) . \text { time, }
$$

where $V K(r)$ denotes the money value of the capital stock in region $r$, and $N E T I N V(r)$, the money value of net investment.

In a static simulation, with time equal to zero, we see from equation (8) that the percentage change in the capital stock $q k$ is also zero. Sometimes however we wish to impose some non-zero change in capital stocks. To that end we introduce into the accumulation equation a region-generic shift factor $S Q K W O R L D$ and a region-specific factor $S Q K(r)$. Incorporating those factors we obtain the final version of the levels equation,

$$
Q K(r)=S Q K W O R L D . S Q K(r)\left[Q K O(r)+\int_{\text {TIME_o }}^{\text {TIME }} N E T I N V(r) d T\right]
$$


the differential equation,

$$
V K(r) \cdot q k(r)=V K(r)[s q k w o r l d+s q k(r)]+100 \operatorname{NETINV}(r) . \text { time },
$$

and the model code,

$$
\begin{aligned}
& \text { Equation E_qk \#capital accumulation\# (all,r,REG) } \\
& \operatorname{VK}(r) * q k(r)=\operatorname{VK}(r) *[\operatorname{sqkworld}+\operatorname{sqk}(r)]+100 * \operatorname{NETINV}(r) * \text { time; }
\end{aligned}
$$

\section{Financial assets and associated income flows}

As discussed in the introduction, to model international capital mobility we need to distinguish between asset location and ownership; to do this, we introduce financial assets. In GTAP-Dyn, regional households do not own physical capital; only firms do. Households own not physical capital but financial assets, which represent indirect claims on physical capital.

In this section, we show how the model determines agents' financial assets and liabilities, and the associated income receipts and payments. We begin with a discussion of the treatment's general features (subsection 4.1) and a note on notation (subsection 4.2). Stock-flow accumulation relations determine two key financial asset variables (subsection 4.3); with those as constraints, we use an atheoretic mechanism to determine the composition of firms' liabilities and regional households' assets (subsection 4.4). We complete the module with equations for the assets and liabilities of the global financial intermediary (subsection 4.5) and income flows associated with financial assets (subsection 4.6).

\subsection{General features}

Besides the prime motivation to take account of international capital mobility, several other requirements have shaped the treatment of financial assets in GTAP-Dyn. For reasons discussed below (section 5.1), we do not enforce rate-of-return equilibration over the short run. This means that we need to represent gross ownership positions. It is not enough, for example, to know a region's net foreign assets; we must know both its gross foreign assets and its gross foreign liabilities, since their rates of return may differ.

To limit the burden of data construction for the extended model, and because data on foreign assets and liabilities are limited and inconsistent, we prefer a treatment of foreign assets that is parsimonious in its data requirements. We also want the treatment 
to accommodate the salient empirical regularity of local specialization, that countries do not hold globally balanced asset portfolios, but specialize strongly in holding local assets.

We do not aim with the new treatment to give a full or accurate representation of financial variables. The financial assets in GTAP-Dyn are there not to provide a good representation of financial assets in the real world, but to let us represent international capital mobility without creating leaks in the foreign accounts. Our treatment of financial assets accordingly is minimalist and highly stylized.

Influenced by these considerations, we determine some broad features of the financial assets module. First and fundamentally, we elect not to adopt a full finance-theoretic treatment of financial assets, but to take an ad hoc or heuristic approach. The attraction of a finance-theoretic approach is that it would let us account in a principled way for investors' holding assets with different rates of return, rather than only the highestyielding asset. It would recognize that investors are concerned not only with return but also with risk. It would relate their decisions on risk-return tradeoffs and their consumption and saving behavior to the same set of underlying preferences, preserving thereby the rigor of the welfare analysis.

On the other hand, introducing a finance-theoretic treatment would add greatly to the complexity of the model, and yet create perhaps as many difficulties as it would solve. There are a number of paradoxes in international financial behavior, empirical regularities that are difficult to account for theoretically. Most relevantly here, it is difficult to account for observed disparities between countries in rates of return, which far exceed those predicted with simple finance-theoretic models, plausible behavioral parameter settings, and observed risk levels. This does not rule out the finance-theoretic approach, but it does make the cost-benefit balance less attractive. On balance then, we elect not to implement such a treatment in this version of GTAP-Dyn, while acknowledging its attractiveness as an area for future research.

After this basic decision, there are several further design decisions to make. First, we must decide which physical assets should back financial assets; in other words, to which assets should financial assets represent indirect claims. To allow for international capital mobility, we must include physical capital in this set; we may also include primary factors (endowment commodities in GTAP jargon) other than labor. In the standard GTAP data base, at the time of writing (McDougall, Elbehri and Truong, 1998), these are two: agricultural land, and other natural resources (mineral deposits, fisheries, and forests). It would be more logical to let all these back financial assets, but it is easier to let only physical capital back financial assets. In this version of the model, we take the easier approach. Accordingly, in GTAP-Dyn, firms own physical capital, but rent 
land and natural resources. Regional households, conversely, own land and natural resources, which they lease to firms, and financial assets, which may be construed as indirect claims on physical capital.

The next question is which classes of financial assets to represent in the model. There are in the real world three broad classes of financial assets, money, debt, and equity, divided in turn into many subclasses. Recognizing more asset classes would potentially improve the realism of the model. On the other hand, for reasons discussed above, realism in the representation of financial assets is not a priority for this model. In light of this, and consistent with our stance that the role of the financial asset module is to support international capital mobility rather than to depict the financial sector realistically, we include in the model just one asset class, equity. Accordingly, in GTAPDyn, firms have no liabilities, and only one asset, physical capital. By the fundamental balance sheet identity (assets = liabilities + proprietorship), shareholder equity in the firm is equal in value to the physical capital that the firm owns.

Next we ask which agents can hold equity in firms. The simplest design would be to let all regional households hold equity in firms in all regions. This, however, would require bilateral data on foreign assets and liabilities. Unfortunately the available data are insufficient (pertaining mainly to foreign direct investment, not portfolio investment or bond holdings) and internally inconsistent. To minimize the data requirements, we adopt instead the fiction of a global trust that serves as a financial intermediary for all foreign investment. Regional households, in GTAP-Dyn, do not hold equity directly in foreign firms, but only in local firms and the global trust. The global trust in turn holds equity in firms in all regions. The trust has no liabilities, and no assets other than its equity in regional firms; so, by the balance sheet identity, total equity in the trust is equal in value to total equity held by the trust.

A minor defect of this treatment is that it leads the model to misreport foreign asset holdings. We identify each region's equity in the global trust with its foreign assets, when in fact some portion of it represents indirect ownership of local assets. This misreporting is trivial for small regions, but more considerable for large regions such as the United States.

Figure 1 summarizes the financial asset framework. Firms in each region $r$ have a value $W Q_{-} F I R M(r)$, of which the local regional household owns $W Q \operatorname{HFIRM}(r)$ and the global trust WQTFIRM $(r)$. The global trust in turn is owned by the regional households, each region $r$ owning equity $\operatorname{WQHTRUST}(r)$. The total financial wealth of the regional household comprises equity $W Q H F I R M(r)$ in local firms and equity WQHTRUST $(r)$ in the global trust. We discuss these relations further in subsections 4.3 and 4.5 . 
One further matter remains to be discussed, the concepts of income from and investment in physical and financial assets. We count as income the earnings of the asset, but not capital gains or losses arising from asset price changes. For physical capital, we also exclude physical depreciation from the definition of income (just as in standard GTAP). For equity in firms or in the global trust, we count as investment the money value of net change in the quantity of the entity's assets, but exclude capital gains.

This treatment has two merits. First, it imposes consistency between income and investment in financial assets: both exclude capital gains, so saving (calculated as total investment in financial assets) is consistent with income. Second, it supports a simple decomposition of change in proprietorship. Consider an entity that has no liabilities but owns several assets. Let $W_{A i}$ denote the value of assets of type $i$, and $W=\sum_{i} W_{A i}$, total asset value. Then percentage change $w$ in total asset value is given by the equation $W w=\sum_{i} W_{A i}\left(p_{A i}+q_{A i}\right)$, where $p_{A i}$ denotes percentage change in the price of asset $i$, and $q_{A i}$, percentage change in the quantity. We can use this equation to decompose this change in total asset value into two components, the money value of net change in the quantity of the entity's assets, $(1 / 100) \sum_{i} W_{A i} q_{A i}$, and the money value of change in the prices of the quantity's assets, $(1 / 100) \sum_{i} W_{A i} p_{A i}$.

Now by the balance sheet identity, total proprietorship in the firm is equal to total asset value $W$, so $w=p_{Q}+q_{Q}$, where $p_{Q}$ and $q_{Q}$ denote percentage change in the price and volume of the firm's stock. We can compose this into an investment component, $(1 / 100) W q_{Q}$, and a capital gain component, $(1 / 100) W p_{Q}$. Then, by our conventional definition of investment, $W q_{Q}=\sum_{i} W_{A i} q_{A i}$, so $W p_{Q}=\sum_{i} W_{A i} p_{A i}$; that is, the price of equity in the firm is proportional to an index of prices of the firm's assets. Thus, the price and quantity components of change in total proprietorship equate to the corresponding components of change in total assets.

Another way to look at this is to imagine that firms and the trust fully distribute their net earnings as dividends to shareholders, and fund their net asset purchases entirely through new stock issues. Under this supposition, the value of dividends coincides with the GTAP-Dyn definition of income, and the value of stock issues with the GTAP-Dyn definition of financial investment.

\subsection{Notation}

To present this accounting framework we use a systematic notational convention. Percentage change variables are written in lower case; upper case variables are data coefficients, parameters, levels variables, or ordinary change variables. In general, the first character of a variable or a coefficient shows its type: $W$ (wealth) for asset values, 
and $Y$ for income flows. The second character identifies the asset type: in the current version of the model, this is always $Q$ for eQuity. The third character indicates the sector that owns the asset, or receives the income it generates, while the fourth character identifies the sector that owes the asset, or pays the associated income. For example, $F$ designates investment in regional firms, $T$ denotes investment in the global trust, and $H$ stands for investment by the regional household. Thus, a name beginning with $W Q H F$ refers to the wealth in equity owned by the regional household and invested in domestic firms, while a name beginning with $Y Q H F$ refers to the income from equity paid to the regional household by the domestic firms. An underscore is used in the cases where the distinction pertaining to a particular character is not in point. The underscore is left out if it is located at the end of the name.

\subsection{Asset accumulation}

The financial assets module revolves around two key variables: the ownership value of firms in region $r$, and the equity holdings of the household in region $r$. Both these are given, directly or indirectly, by accumulation relations.

In GTAP-Dyn, firms buy intermediate inputs, hire labor, and rent land, but own fixed capital. They have no debt. In accounting terms they have no liabilities, and no assets except fixed capital. Conversely, only firms own fixed capital. So the ownership value $W Q_{-} F I R M(r)$ of firms in region $r$ is equal to the value of their fixed capital, which is the value of all local fixed capital, which is equal to the product of the corresponding price and quantity:

$$
W Q_{-} F I R M(r)=V K(r)=P C G D S(r) \cdot Q K(r),
$$

where $P C G D S(r)$ denotes the price of capital goods in region $r$. Differentiating, we obtain

$$
w q_{-} f(r)=p c g d s(r)+q k(r),
$$

where $w q_{-} f(r)$ denotes percentage change in $W Q_{-} F I R M(r)$, and $p c g d s(r)$, percentage change in $P C G D S(r)$; in the model, we write

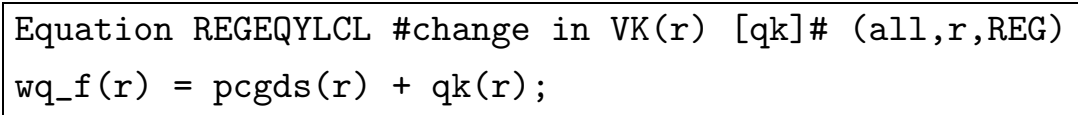

Thus the total equity value of each region's firms is given indirectly by the capital accumulation equation, equation (10).

For future use we note that by the conventions discussed in section 4.1, the price $P Q_{-} F I R M(r)$ of equity in firms in region $r$ is proportional to the price of capital goods 
in region $r$,

$$
p q_{-} f(r)=p c g d s(r),
$$

where $p q_{-} f$ denotes percentage change in $P Q_{-} F I R M$.

As with capital stocks and investment, we use the variable time to capture the intrinsic dynamics of regional wealth and savings. We have for the regional household's ownership of domestic assets the accumulation equation

$$
W Q H F I R M(r)=P Q_{-} F I R M(r) \int_{\text {TIME_o }}^{\text {TIME }} Q Q H F I R M(r) d T,
$$

where $P Q_{-} F I R M(r)$ is the price of stocks in local firms in region $r$, and $Q Q H F I R M(r)$ is the number of stocks purchased by the regional household. Similarly, for the regional household's equity in the global trust, we have

$$
\text { WQHTRUST }(r)=\text { PQTRUST } \int_{\text {TIME_O }}^{\text {TIME }} \text { QQHTRUST }(r) d T,
$$

where PQTRUST is the price of equity in the global trust, and QQHTRUST $(r)$ is the volume of equity purchases by the regional household. Then total wealth of the regional household,

$$
\begin{aligned}
& W Q H H L D(r)=P C G D S(r) \int_{\text {TIME_O }}^{\text {TIME }} Q Q H F I R M(r) d T \\
& + \text { PQTRUST } \int_{\text {TIME_O }}^{\text {TIME }} \text { QQHTRUST }(r) d T .
\end{aligned}
$$

Differentiating, and substituting for $p q_{-} f$ from equation (12), we obtain:

$$
\begin{aligned}
& \text { WQHHLD }(r) \cdot w q h(r)= \\
& \quad \text { WQHFIRM }(r) \cdot p c g d s(r)+\text { WQHTRUST }(r) \cdot p q t r u s t \\
& \quad+100(\operatorname{VQHFIRM}(r)+\operatorname{VQHTRUST}(r)) \text { time }
\end{aligned}
$$

where pqtrust denotes percentage change in $\operatorname{PQTRUST}, \operatorname{VQHFIRM}(r)$, the value of new investment by the regional household in domestic firms in region $r$,

$$
\operatorname{VQHFIRM}(r)=\operatorname{PCGDS}(r) \cdot Q Q H F I R M(r),
$$

and $\operatorname{VQHTRUST}(r)$ the value of new investment by the regional household in the global trust,

$$
\operatorname{VQHTRUST}(r)=\operatorname{PQTRUST}(r) \cdot \mathrm{QQHTRUST}(r) .
$$


Now total investment by the regional household in domestic and foreign equity is equal to saving by the regional household - that is, $\operatorname{VQHFIRM}(r)+\operatorname{VQHTRUST}(r)=$ $S A V E(r)$, where $S A V E(r)$ denotes savings in region $r$. So equation (13) simplifies to

$$
\begin{aligned}
& \text { WQHHLD }(r) \cdot w q h(r)= \\
& \quad \text { WQHFIRM }(r) \cdot p c g d s(r)+\text { WQHTRUST }(r) \cdot \text { pqtrust } \\
& \quad+100 . S A V E(r) . t i m e .
\end{aligned}
$$

In the code, we write

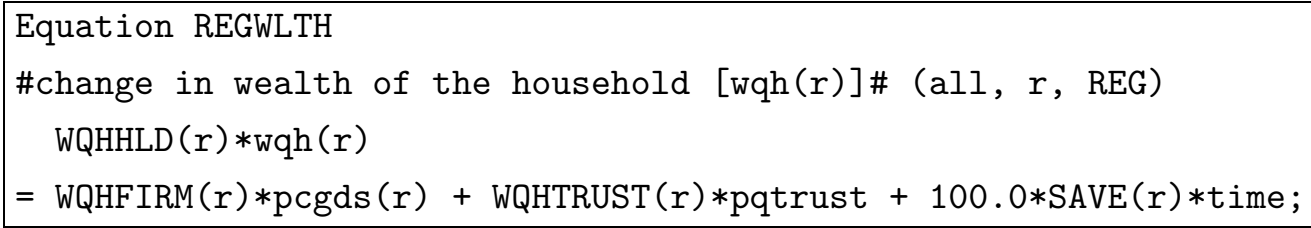

\subsection{Assets and liabilities of firms and households}

In subsection 4.3 , we determined the value $W Q_{-} F I R M$ of equity in firms in each region. As shown in figure 1, this equity has two components, equity belonging to the local regional household, $\operatorname{WQHFIRM}(r)$, and that belonging to the global trust, WQTFIRM $(r)$ :

WQHFIRM WQTFIRM

Differentiating, we obtain:

$$
\begin{aligned}
& W Q_{-} F I R M(r) . w q_{-} f(r)= \\
& \quad W Q H F I R M(r) . w q h f(r)+W Q T F I R M(r) . w q t f(r) .
\end{aligned}
$$

where $w q h f(r)$ and wqtf $(r)$ denote percentage changes in WQHFIRM and WQTFIRM $(r)$. wqhf This appears in the model as:

Equation EQYHOLDFNDLCL \#total value of firms in region $r \#$ (all, $r, R E G$ ) WQ_FIRM $(r) *$ Wq_f $(r)=\operatorname{WQHFIRM}(r) * w q h f(r)+\operatorname{WQTFIRM}(r) * \operatorname{wqtf}(r)$;

Also in subsection 4.3, we determined the wealth in equity of the regional households, $W Q H H L D$. As shown in figure 1, this also has two components, equity in domestic regional firms, WQHFIRM, and in the global trust, WQHTRUST.

$$
W Q H H L D(r)=W Q H F I R M(r)+W Q H T R U S T(r) .
$$

WQHHLD

WQHFIRM WQHTRUST 
Differentiating, we obtain:

$$
\begin{aligned}
& W Q H H L D(r) \cdot w q h(r)= \\
& \quad W Q H F I R M(r) \cdot w q h f(r)+W Q H T R U S T(r) \cdot w q h t(r),
\end{aligned}
$$

where $w q h f(r)$, and $w q h t(r)$ denote percentage changes in $\operatorname{WQHFIRM}(r)$ and WQHTRUST $(r)$. This appears in the model as:

Equation EQYHOLDWLTH \#total wealth of the household\# (all, $r, R E G)$
$\operatorname{WQHHLD}(r) * \operatorname{wqh}(r)=\operatorname{WQHFIRM}(r) * \operatorname{wqhf}(r)+\operatorname{WQHTRUST}(r) * \operatorname{wqht}(r)$

Thus far, for each region $r$ we have two accounting identities, equations (15) and (17), and three variables to determine, WQHFIRM, WQTFIRM, and WQHTRUST. Equivalently, for each region the identities suffice to determine the net value of foreign assets,

$$
W Q H T R U S T(r)-W Q T F I R M(r)=W Q H H L D(r)-W Q_{-} F I R M,
$$

but not gross foreign assets and liabilities, WQHTRUST(r) and WQTFIRM $(r)$. Obviously there are many different gross foreign asset positions consistent with the net position.

In this model, we do not make use of portfolio allocation theory, so we have no theory explaining the gross ownership position. Over the long run, rates of return on capital are equalized across regions. With no portfolio allocation theory, investors care only about returns, so with returns equalized the allocation of assets is arbitrary. Over the short run, we allow inter-regional differences in rates of return (subsection 5.1). We need investors to hold several assets (since net foreign ownership positions must be non-zero), but we have no theory explaining why investors would hold any assets other than the highest-yielding. Accordingly, we can determine portfolio allocation over the short or long run only by applying some atheoretic rule.

In selecting a portfolio rule, we have some constraints to guide us. First and most obviously, the three variables $\operatorname{WQHFIRM}(r), \operatorname{WQHTRUST}(r)$, and $\operatorname{WQTFIRM}(r)$ must satisfy the two identities (15) and (17).

Furthermore, we want to obtain positive values for those three variables, if possible (and it is possible, provided that $W Q H H L D(r)$ and $W Q_{-} F I R M(r)$ are positive). While it is possible in the real world to short-sell stocks, we do not observe large long-lasting negative equity holdings. If we nevertheless allowed negative holdings in the model, they would be liable to generate strange welfare results. If for example we allowed the global trust to hold negative equity in Taiwan, then the income of the trust, and 
consequently, the foreign asset income of each region, would vary not directly but inversely with Taiwanese capital rentals. Given the real-world absence of stable negative equity holdings, this inverse relationship would be unrealistic.

Finally, we want the allocation rule to preserve as nearly as possible the initial allocation of each region's wealth between domestic and foreign assets. One of the objectives of the asset treatment is to allow the model to respect the empirical regularity, that regions tend to specialize their portfolios strongly in their own domestic assets. If the initial data base respects this, we want updated data bases to respect it also.

One possible approach is to assume that each region allocated its wealth between domestic and foreign assets in fixed proportions. This is simple and in some ways appealing, but it has one defect: it makes it too easy for foreign liabilities to become negative. A negative shock to productivity in Taiwan, for example, might cause the value of capital located in Taiwan to fall more rapidly than the value of equity owned by Taiwanese. With the fixed shares approach, the value of domestic equity owned by Taiwanese might easily come to exceed the value of the Taiwanese capital stock, so that the value of foreign ownership of Taiwanese industry would become negative. As discussed above, we wish to avoid such outcomes.

If conversely we assumed that the composition of the source of funds was fixed in each region, so that foreign and domestic equity in local capital varied in fixed proportion, we would be assured that foreign ownership of local capital would not turn negative; but growth in the local capital stock might easily lead to negative local ownership of foreign assets.

To avoid negative values in both gross foreign assets and gross foreign liabilities, we need a more sophisticated approach. We find this in entropy theory. In particular, cross-entropy minimization gives us a way of dividing a strictly positive total into strictly positive components, subject to various constraints, while staying as close as possible to the initial shares. A full exposition of the relevant concepts would take us too far afield here; see for example Kapur and Kesavan (1992), for a modern treatment emphasizing aspects of interest to economists.

Cross entropy is an indicator of the degree of divergence between two partitions $S_{i}, i=1, \ldots, n$ of a total value. Writing $S_{i}(0)$ for the initial shares, and $S_{i}(1)$ for the final shares, the cross entropy is

$$
\sum_{i} S_{i}(1) \log \frac{S_{i}(1)}{S_{i}(0)}
$$


This takes a minimum when, for all $i, S_{i}(1)=S_{i}(0)$; that is, when the final shares are equal to the initial shares (see e.g. Kapur and Kesavan, 1992).

The advantages of the cross-entropy approach become apparent when we impose constraints on the final shares; for example, imposing certain subtotals. For a wide variety of constraints, the constrained optimization problem leads to a simple and transparent set of first-order conditions. Also, with strictly positive initial shares, we are (constraints permitting) guaranteed strictly positive final shares.

We are concerned with two sets of shares: the shares of domestic and foreign equity in domestic wealth, and the shares of domestic and foreign funds in ownership of local capital. With each of these we associate a cross-entropy measure. For shares in domestic wealth in region $r$, the cross entropy,

$$
\begin{aligned}
& C E H H L D(r)=W Q H F I R M S H(r) \cdot \log \frac{W Q H F I R M S H(r)}{W Q H F I R M S H \_0(r)}
\end{aligned}
$$

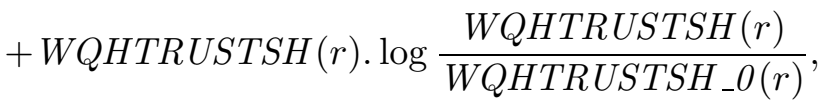

where WQHFIRMSH(r) denotes the current share of local firms, and $\operatorname{WQHTRUSTSH}(r)$ the current share of the global trust, in the equity portfolio of the household in region $r$, and WQHFIRMSH_O(r) and WQHTRUSTSH_O $(r)$ denote the initial levels of those shares.

Now by definition, we have

$$
\begin{aligned}
& W Q H F I R M S H(r)=\frac{W Q H F I R M(r)}{W Q H H L D(r)}, \\
& W Q H F I R M S H_{-} O(r)=\frac{W Q H F I R M_{-} O(r)}{W Q H H L D_{-} O(r)}, \\
& W Q H T R U S T S H(r)=\frac{W Q H T R U S T(r)}{W Q H H L D(r)}, \\
& W Q H T R U S T S H_{-} O(r)=\frac{\text { WQHTRUST_O }(r)}{W Q H H L D_{-} 0(r)},
\end{aligned}
$$

Substituting these into equation (19), we obtain

$$
\begin{aligned}
& W Q H H L D(r) . C E H H L D(r) \\
& =W Q H F I R M(r) \cdot \log \frac{W Q H F I R M(r)}{W Q H F I R M_{-} 0(r)} \\
& + \text { WQHTRUST }(r) \cdot \log \frac{\text { WQHTRUST }(r)}{\text { WQHTRUST_O }(r)}
\end{aligned}
$$




$$
-W Q H H L D(r) \cdot \log \frac{W Q H H L D(r)}{W Q H H L D \_0(r)} .
$$

Since $W Q H H L D(r)$ and $W Q H H L D \_O(r)$ are given, maximizing $C E H H L D(r)$ is equivalent to maximizing

$$
F H H L D(r)=C E H H L D(r)+W Q H H L D(r) \cdot \log \frac{W Q H H L D(r)}{W Q H H L D \_0(r)} .
$$

Then

$W Q H H L D(r) . F H H L D(r)=$

$$
W Q H F I R M(r) \cdot \log \frac{W Q H F I R M(r)}{W Q H F I R M_{-} 0(r)}+W Q H T R U S T(r) \cdot \log \frac{W Q H T R U S T(r)}{W Q H T R U S T \_0(r)} .
$$

Similarly, maximizing the cross-entropy associated with the local capital ownership shares is equivalent to maximizing $\operatorname{FFIRM}(r)$, where

$W Q_{-} \operatorname{FIRM}(r) . \operatorname{FFIRM}(r)=$

$$
W Q H F I R M(r) \cdot \log \frac{W Q H F I R M(r)}{W Q H F I R M \_0(r)}+W Q T F I R M(r) \cdot \log \frac{W Q T F I R M(r)}{W Q T F I R M \_0(r)} .
$$

We seek to minimize a weighted sum of the two cross-entropies:

$$
\begin{aligned}
W S C E(r)= & R I G W Q H(r) \cdot W Q H H L D(r) \cdot C E H H L D(r) \\
& +R I G W Q_{-} F(r) \cdot W Q_{-} F I R M(r) \cdot C E F I R M(r) .
\end{aligned}
$$

The two cross-entropies are weighted by the corresponding total values, $W Q H H L D(r)$ and $W Q_{-} F I R M(r)$, and explicitly by the rigidity parameters $R I G W Q H(r)$ and $R I G W Q_{-} F(r)$. If $R I G W Q H(r)$ is assigned a high value, and $R I G W Q_{-} F(r)$ a low one, then the solution will, if possible, keep the allocation of household wealth nearly fixed, and put most of the onus of adjustment on the source shares for equity in local firms. If $R I G W Q_{-} F(r)$ is assigned a high value, and $R I G W Q H(r)$ a low one, the equity source shares will tend to remain near their initial values, and the household wealth allocation shares do most of the adjusting.

From the foregoing, minimizing $W S C E$ is equivalent to minimizing the somewhat simpler

$$
\begin{aligned}
F= & R I G W Q H(r) \cdot W Q H H L D(r) \cdot F H H L D(r) \\
& +R I G W Q \_F(r) \cdot W Q \_F I R M(r) \cdot F F I R M(r)
\end{aligned}
$$




$$
\begin{aligned}
& =R I G W Q H(r)\left(W Q H F I R M(r) \cdot \log \frac{W Q H F I R M(r)}{W Q H F I R M \_0(r)}\right. \\
& \left.+W Q H T R U S T(r) \cdot \log \frac{W Q H T R U S T(r)}{W Q H T R U S T \_O(r)}\right) \\
& +R I G W Q \_F(r)\left(W Q H F I R M(r) . \log \frac{W Q H F I R M(r)}{\text { WQHFIRM_O }(r)}\right. \\
& \left.+W Q T F I R M(r) \cdot \log \frac{W Q T F I R M(r)}{W Q T F I R M_{-} 0(r)}\right) .
\end{aligned}
$$

To determine the three wealth variables, we minimize this objective function subject to the constraints (17) and (15). The Lagrangean contains corresponding multipliers, $X W Q H H L D(r)$ for the household wealth constraint (17) and XWQ_FIRM $(r)$ for the firm value constraint (15). The first-order conditions include the two constraints, and three equations corresponding to the three net wealth variables.

Thus, differentiating the Lagrangean with respect to foreign equity in domestic capital, $\operatorname{WQTFIRM}(r)$, we obtain the first-order condition

$$
X W Q_{-} F I R M(r)=R I G W Q_{-} F(r)\left(\log \frac{W Q T F I R M(r)}{W Q T F I R M_{-} 0(r)}+1\right) .
$$

Differentiating again, we obtain

$$
x w q_{-} f(r)=R I G W Q_{-} F(r) \cdot w q t f(r),
$$

where $x w q_{-} f(r)$ denotes change in the Lagrange multiplier $X W Q_{-} F I R M(r)$. In TABLO $x w q_{-} f$ code, we have:

Equation EQYHOLDFNDHHD
\#eqty holdings of trust in the firms [wqtf $(r)] \#$
$($ all, $r, R E G)$
xwq_f $(r)=$ RIGWQ_F $(r) * \operatorname{wqtf}(r)$;

Likewise, for domestic ownership of foreign equity, we have the levels form of the first-order condition,

$$
X W Q H H L D(r)=R I G W Q H(r)\left(\log \frac{W Q H T R U S T(r)}{W Q H T R U S T \_0(r)}+1\right)
$$

the differential form of the first-order condition,

$$
x w q h(r)=R I G W Q H(r) \cdot w q h t(r),
$$

where $x w q h(r)$ denotes change in the Lagrange multiplier $X W Q H H L D(r)$; and the $\quad x w q h$ 
TABLO code

Equation EQYHOLDHHDFND
\#shift variable for the wealth of hhlds $[\operatorname{xwqh}(r)] \#$
$(\operatorname{all}, r, R E G)$
$\operatorname{xwqh}(r)=\operatorname{RIGWQH}(r) * \operatorname{wght}(r) ;$

Finally, for domestic ownership of domestic equity, we have the levels form of the first-order condition,

$$
\begin{aligned}
& X W Q H H L D(r)+X W Q_{-} F I R M(r)= \\
& \quad\left(R I G W Q H(r)+R I G W Q_{-} F(r)\right)\left(\log \frac{W Q H F I R M(r)}{W Q H F I R M_{-} 0(r)}+1\right)
\end{aligned}
$$

the differential form of the first-order condition,

$$
x w q h(r)+x w q_{-} f(r)=\left(R I G W Q H(r)+R I G W Q_{-} F(r)\right) w q h f(r),
$$

and the TABLO code

Equation EQYHOLDHHDLCL
\#shift variable wealth of firms [xwq_f(r)]\#
$($ all, $r, R E G)$
$[R I G W Q H(r)+$ RIGWQ_F $(r)] * w q h f(r)=\operatorname{xwqh}(r)+\operatorname{xwq} f(r) ;$

Note that, substituting for wqtf from equation (20) and for wqht from equation (21) into equation (22), we obtain

$$
\begin{aligned}
& \left(R I G W Q H(r)+R I G W Q_{-} F(r)\right) w q h f(r)= \\
& R I G W Q H(r) w q h t(r)+R I G W Q_{-} F(r) w q t f(r) .
\end{aligned}
$$

This equation shows that the adjustment in $W Q H F I R M(r)$ is an average of the adjustments in WQTFIRM $(r)$ and WQHTRUST $(r)$.

Note also that if, for example, we assign a high value to $R I G W Q H(r)$ and a low value to $R I G W Q_{-} F(r)$, then $x w q h(r)$ will assume a relative large value, and $x w q_{-} f(r)$ a relatively small value; so that $x w q h(r) \approx R I G W Q H(r) \cdot w q h f(r)$; so that $w q h f(r) \approx$ $w q h t(r)=R I G W Q H(r)^{-1} x w q h(r)$; that is, the household wealth allocation shares are nearly fixed, as previously asserted. 


\subsection{Assets and liabilities of the global trust}

There are three accounting identities associated with the global trust. First, the value of assets owned by the global trust, WQTRUST, is equal to the sum across regions of foreign ownership of firms:

$$
W Q T R U S T=\sum_{r} W Q T F I R M(r)
$$

In percentage change form, we have:

$$
W Q T R U S T . w q t=\sum_{r} W Q T F I R M(r) . w q t f(r),
$$

where wqt is the percentage change in WQTRUST; in the TABLO code:

The second identity is that the value of the trust, WQ_TRUST, is equal to the sum

of the regions' equity in the trust, that is, to the sum across regions of ownership of foreign assets:

$$
W Q_{-} T R U S T=\sum_{r} W Q H T R U S T(r)
$$

In percentage change form,

$$
W Q_{-} T R U S T . w q_{-} t=\sum_{r} W Q H T R U S T(r) . w q h t(r),
$$

where $w q_{-} t$ is the percentage change in $W Q_{-} T R U S T$; in the TABLO code, Equation TOTGFNDPROP \#value of trust as total ownership of trust\# WQ_TRUST*wq_t $=\operatorname{sum}\{\mathrm{s}, \mathrm{REG}, \operatorname{WQHTRUST}(\mathrm{s}) * \operatorname{wqht}(\mathrm{s})\}$;

Finally, the total value of the trust is equal to the total value of its assets:

$$
W Q_{-} T R U S T=W Q T R U S T
$$

This equation as written would be redundant in the model, since it is implicit in other relations. The accumulation equations, together with the equivalence of global investment and global saving, ensure that the total value of physical capital is always equal to the total value of financial asset ownership by regions: so

$$
\sum_{r} W Q_{-} F I R M(r)=\sum_{r} W Q H H L D(r)
$$


Then

$$
\begin{aligned}
W Q_{-} T R U S T & =\sum_{r} W Q H T R U S T(r) \quad \text { by equation }(26) \\
& =\sum_{r}(W Q H H L D(r)-W Q H F I R M(r)) \quad \text { by equation }(15) \\
& =\sum_{r} W Q H H L D(r)-\sum_{r} W Q H F I R M(r) \\
& =\sum_{r} W Q_{-} F I R M(r)-\sum_{r} W Q H F I R M(r) \quad \text { by equation }(27) \\
& =\sum_{r}\left(W Q_{-} F I R M(r)-W Q H F I R M(r)\right) \\
& =\sum_{r} W Q T F I R M(r) \quad \text { by equation }(17) \\
& =W Q T R U S T \quad \text { by equation }(24),
\end{aligned}
$$

as was to be shown.

To verify that simulation results satisfy the identity, we include in the model the equation

$$
\text { WQTRUST }=\text { WTRUSTSLACK.WQ_TRUST, }
$$

where WTRUSTSLACK denotes an endogenous slack variable. In percentage change WTRUSTSLACK form,

$$
w q t=w q_{-} t+w \text { trustslack, }
$$

where wtrustslack denotes percentage change in WTRUSTSLACK. In the TABLO code,

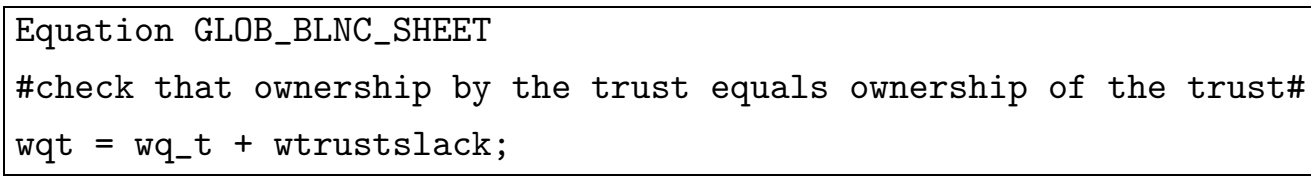

Provided that the model data base respects the asset accounting identities (and assuming no errors in the equations), the variable wtrustslack is endogenously equal to zero in any simulation. Thus the result for the slack variable provides a check on the validity of the model. Figure 1 illustrates these accounting relations.

Corresponding to equation (25) for asset values we have a price equation. As discussed in section 4.1, we can divide growth in assets and in proprietorship into matching investment and capital gain components. For the global trust, equating the capital gain components of assets and proprietorship yields the equation

$$
\text { pqtrust }=\sum_{r} \frac{W Q T F I R M(r)}{W Q T R U S T} p c g d s(r)
$$




$$
=\sum_{r} W Q T_{-} F I R M S H R(r) \cdot p c g d s(r)
$$

where $W Q T T_{-} F I R M S H R(r)$ denotes the share of region $r$ equities in total assets of the global trust. In the code, this becomes

Equation PKWRLD
\#change in the price of equity in the global fund\#
pqtrust = sum $r$, REG, WQT_FIRMSHR $(r) * \operatorname{pcgds}(r)\} ;$

\subsection{Income from financial assets}

Having determined stocks of financial assets in the foregoing subsections, we now determine the associated income flows. We do this in three stages. First, we determine payments from firms to households and to the global trust. Second, we calculate the total income of the global trust, and determine payments from the trust to regional households. Third, we calculate the equity income of regional households as the sum of receipts from local firms and from the global trust.

For an overview of the equity income flows, we refer to figure 2. Firms in region $r$ distribute to shareholders equity income payments $Y Q_{-} F I R M(r)$, of which $\operatorname{YQHFIRM}(r)$ goes to the local regional household and $\operatorname{YQTFIRM}(r)$ to the global trust. Summing these receipts $\operatorname{YQTFIRM}(r)$ across regions, we obtain the total income YQTRUST of the global trust. The trust distributes this amongst the regional households, with region $r$ receiving an amount $Y Q H T R U S T(r)$. Thus the total equity income of region $r, Y Q H H L D(r)$, is the sum of receipts $Y Q H F I R M(r)$ from local firms and receipts $Y Q H T R U S T(r)$ from the global trust. This summed with non-equity factor income and indirect taxes yields total regional income $\operatorname{INCOME}(r)$.

We begin the detailed discussion with payments by firms. Firms buy intermediate inputs, hire labor, and rent land, but own fixed capital. By the zero pure profits condition, their profits are equal to the cost of capital services, excluding any factor usage or income taxes, less depreciation. These profits accrue to shareholders. Thus total income payments by firms in region $r$ to shareholders, $Y Q_{-} F I R M(r)$, are equal to net after-tax capital earnings:

$$
Y Q_{-} F I R M(r)=\operatorname{VOA}(\text { "capital", } r)-\operatorname{VDEP}(r),
$$

where $\operatorname{VOA}($ "capital", $r$ ) is the value of capital earnings, and $\operatorname{VDEP}(r)$ is the value of VOA capital depreciation. Differentiating, we obtain

$$
\text { YQ_FIRM }(r) y q_{-} f(r)=
$$




$$
\operatorname{VOA}(\text { "capital", } r)(\operatorname{rental}(r)+q k(r))-\operatorname{VDEP}(r)(p c g d s(r)+q k(r)),
$$

where $y q_{-} f(r)$ denotes the percentage change in income payments by firms in region $r$,

$y q-f$ and rental $(r)$, percentage change in the rental price of capital. In the code, this becomes (somewhat obscurely)

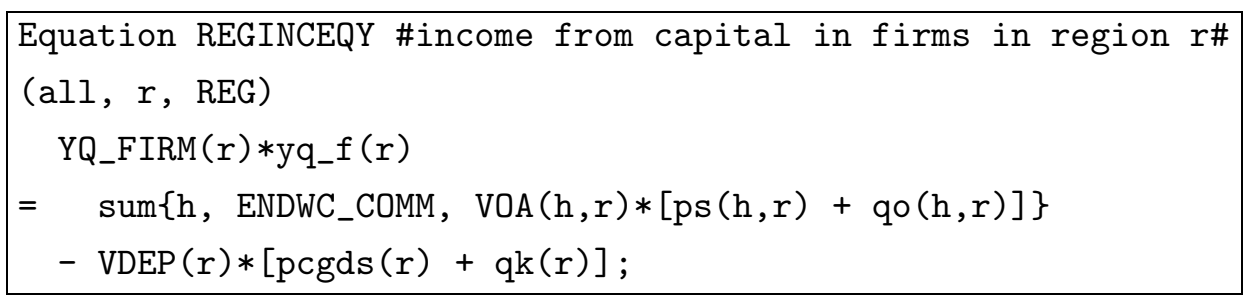

To relate this to the mathematical form of the equation, note that ENDWC_COMM is a set with just one element, "capital", with $p s($ "capital", $r)=\operatorname{rental}(r)$ and $q o($ "capital", $r)=q k(r)$.

Firms distribute payments amongst shareholders in proportion to their shareholdings. The local regional household owns WQHFIRM and the global trust WQTFIRM of a total equity value $W Q_{-} F I R M$ (see subsection 4.4). So for payments $\operatorname{YHFIRM}(r)$ to the local regional household, we have

$$
\operatorname{YQHFIRM}(r)=\frac{W Q H F I R M(r)}{W Q_{-} F I R M(r)} Y Q_{-} F I R M(r) .
$$

Differentiating, we obtain

$$
y q h f(r)=y q_{-} f(r)+w q h f(r)-w q_{-} f(r)
$$

where $y q h f(r)$ denotes the percentage change in $\operatorname{YQHFIRM}(r)$. In the TABLO code,

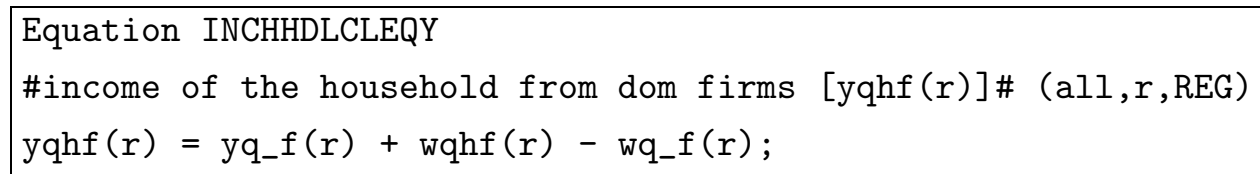

Similarly, payments to the global trust, $\operatorname{YQTFIRM}(r)$, are given by

$$
\operatorname{YQTFIRM}(r)=\frac{W Q T F I R M(r)}{W Q_{-} \operatorname{FIRM}(r)} Y Q_{-} \operatorname{FIRM}(r),
$$

Differentiating, we obtain

$$
y q t f(r)=y q_{-} f(r)+w q t f(r)-w q_{-} f(r)
$$




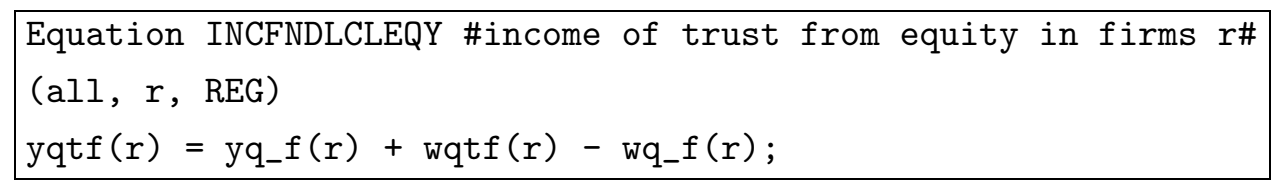

In the second stage we compute total income receipts and the various income payments of the global trust. The total income of the trust, YQTRUST, is equal to the sum of equity receipts from firms in each region. In levels, we express this as:

$$
\text { YQTRUST }=\sum_{r} \operatorname{YQTFIRM}(r)
$$

in percentage changes, as:

$$
y q t=\sum_{r} \frac{\operatorname{YQTFIRM}(r)}{Y Q T R U S T} y q t f(r),
$$

where yqt denotes the percentage change in YQTRUST; and in the TABLO code, as:

Equation INCFNDEQY
\#change in the income of the trust\#
yqt $=\operatorname{sum}\{r, \operatorname{REG},[$ YYTFIRM $(r) /$ YQTRUST] *yqtf $(r)\} ;$

The trust distributes its income amongst its shareholders, so that each region $r$ receives income $Y Q H T R U S T(r)$ in proportion to its ownership share. This is expressed in the levels equation

$$
Y Q H T R U S T(r)=\frac{W Q H T R U S T(r)}{W Q_{-} T R U S T} Y Q T R U S T ;
$$

the differential equation

$$
y q h t(r)=y q t+w q h t(r)-w q_{-} t
$$

where $y q h t(r)$ denotes the percentage change in YQHTRUST; and in the TABLO code

$y q h t$

Equation REGGLBANK \#income of hhld $r$ from its shrs in the trust\#
$(a l l, r, R E G)$
$\operatorname{yqht}(r)=$ yqt + wqht $(r)$ - wq_t;

In the third and final stage we compute the financial asset income of regional households. Total equity income $Y Q H H L D(r)$ of regional household $r$ equals the sum of equity income received from domestic firms and from the global trust:

$$
Y Q H H L D(r)=Y Q H F I R M(r)+Y Q H T R U S T(r) .
$$


In percentage changes,

$$
y q h(r)=\frac{Y Q H F I R M(r)}{Y Q H H L D(r)} y q h f(r)+\frac{Y Q H T R U S T(r)}{Y Q H H L D(r)} y q h t(r),
$$

where $y q h(r)$ denotes percentage change in $Y Q H H L D$; in the TABLO code,

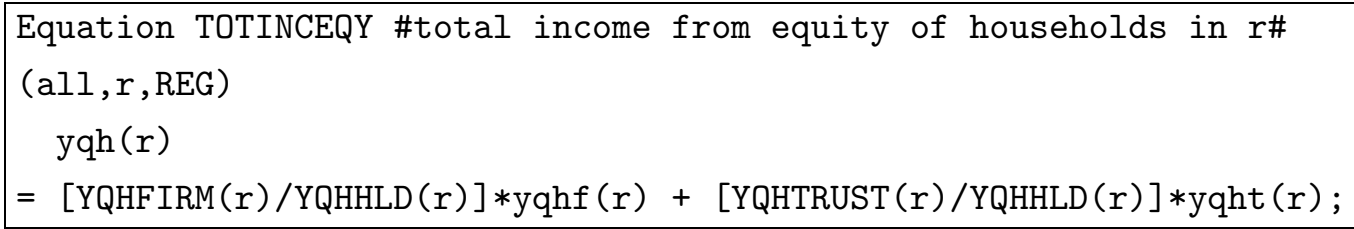

\section{Investment Theory}

In this section we describe a lagged adjustment, adaptive expectations theory of investment. Investors act so as to eliminate disparities in expected rates of return not instantaneously, but progressively through time. Moreover, their expectations of rates of return may be in error, and these errors are also corrected progressively through time. Finally, in estimating future rates of return, they allow for some normal rate of growth in the capital stock; and this normal rate too is an estimated rate that investors adjust through time.

\subsection{The required rate of growth in the rate of return}

In a simple perfect adjustment model of investment, profit-maximizing investors would keep rates of return uniform across regions, since any differences in rates of return would be immediately eliminated by a reallocation of capital from regions with lower rates of return to regions with higher rates. This equalization would apply to net rates of return, so that we might write, for each region $r, \operatorname{RORNET}(r)=R O R C O M M$, where RORNET $(r)$ denotes the net rate of return on capital in region $r$, and RORCOMM the common world rate of return.

If we allow for region specific risk premia $R R I S K(r)$, then we postulate equaliza-

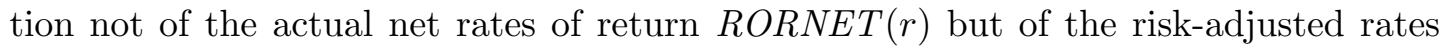
$\operatorname{RORNET}(r)-\operatorname{RRISK}(r)$, so that, for all regions $r, \operatorname{RORNET}(r)=\operatorname{RORCOMM+}$ $R R I S K(r)$. Furthermore, as we find below, it is convenient to express the investment theory in terms of gross rather than net rates of return; anticipating this, we write $R D E P(r)$ for the depreciation rate in region $r$, and obtain for the gross rate of return 
the equilibrium condition

$$
\operatorname{RORGROSS}(r)-\operatorname{RORCOMM-RRISK}(r)-\operatorname{RDEP}(r)=0 .
$$

In principle, the gross rate of return RORGROSS $(r)$ includes both an earnings component and a capital gains component:

$$
\operatorname{RORGROSS}(r)=\frac{R E N T A L(r)}{P C G D S(r)}+R G \_P C G D S(r),
$$

where $\operatorname{RENTAL}(r)$ denotes the rental price of capital in region $r$ and $R G \_P C G D S(r)$, the rate of growth in the purchase price of capital. In practice, with a period-by-period solution method, we do not know the rate of growth in the purchase price of capital, ${ }^{1}$ so we neglect it and define the gross rate of return as the earnings rate only:

$$
\operatorname{RORGROSS}(r)=\frac{\operatorname{RENTAL}(r)}{\operatorname{PCGDS}(r)} .
$$

Differentiating, we obtain the percentage change equation

$$
\operatorname{rorga}(r)=\operatorname{rental}(r)-\operatorname{pcgds}(r)
$$

where rorga $(r)$ denotes percentage change in RORGROSS; and the model code

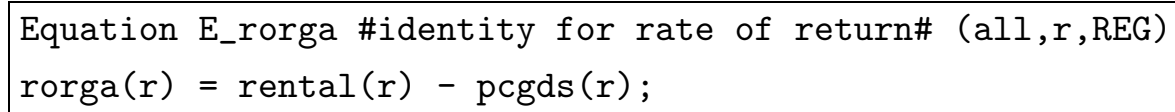

We now consider investment response to sudden (that is, instantaneous) price changes. Sudden price changes may occur, for example, as the result of sudden tax rate changes. Sudden changes to output or input prices affect the capital rental price $R E N T A L(r)$, and thereby the rate of return. In a perfect adjustment model with capital gains, they must be offset by some sudden change in $P C G D S$ or $R G_{-} P C G D S$, or by some sudden offsetting influence on RENTAL, so as to maintain international equality in rates of return as defined in equation (37).

Suppose initially that the supply of capital goods is perfectly elastic. Then a firstround improvement in profitability, that is, a first round positive effect on RENTAL, leads to an increase in the capital stock, increasing output supply (and possibly increasing demand for non-capital inputs) and thereby negating the first-round effect on

\footnotetext{
${ }^{1}$ In fact, we can estimate the backward-looking growth rate, $\lim _{H \rightarrow 0_{-}}(P C G D S(r ; T+H)-$ $P C G D S(r ; T)) / H$, where $P C G D S(r ; x)$ denotes the value of $P C G D S(r)$ at time $T$. This however is liable to differ from the forward looking growth rate, $\lim _{H \rightarrow 0_{+}}(P C G D S(r ; T+H)-P C G D S(r ; T)) / H$, which is the one needed in the rate of return formula.
} 
RENTAL. If the initial shock is sudden, then so also must be the increase in the capital stock; this implies an infinite rate of investment over an infinitesimal time period.

In the real world of course capital stocks do not adjust in this manner. Instantaneous adjustment of capital stocks is precluded by gestation lags, adjustment costs, imperfect elasticity of supply of capital, etc. In a CGE model also, even if other realistic features are lacking, the supply of capital is typically imperfectly elastic.

If we rule out infinite rates of investment, how can rate of return equalization be maintained in the face of sudden shocks affecting profitability? The answer is through sudden changes in the price of capital goods. A sudden improvement in earnings leads to a sudden increase in demand for capital goods, and that in turn to a sudden increase in the price of capital goods. This helps to stabilize the rate of return in two ways. First, it reduces the earnings rate $R E N T A L(r) / P C G D S(R)$. Second, it leads to a decrease in the rate of capital gain $R G_{-} P C G D S$ : as demand for capital goods eases through time after the initial spike, or the supply of capital goods gradually rises, the price of capital goods tends to fall through time after its initial increase.

In our model, we cannot capture the capital gains effect of an increase in demand for capital goods, but we can capture the earnings rate effect. Thus the way appears open in principle to use a perfect adjustment mechanism for investment. Since we do not capture all the effects of the increase in demand for capital, however, it is likely that the model will require unrealistically large increases in the price of capital goods and in the level of investment.

Indeed, there are several reasons why the model would tend to exaggerate investment volatility, some already mentioned, some not:

- The model does not capture the capital gain effect of capital goods price changes.

- As we typically use it in dynamic simulations, the model assumes perfect capital mobility within regions. Accordingly, it overstates the elasticity of supply of capital goods.

- The model does not incorporate other real-world effects such as gestation lags or adjustment costs.

For all these reasons, the perfect adjustment approach is unrealistic in the context of this model. We pursue accordingly a lagged adjustment approach. Recalling equation (36), we rewrite it as

$$
\operatorname{RORGROSS}(r)-\operatorname{RORGTARG}(r)=0,
$$


where RORGTARG(r) denotes the target rate of return in region $r$. To move to a RORGTARG lagged adjustment approach, we replace this in turn by

$$
R R G \_R O R G(r)=L A M B R O R G(r) * \log \frac{R O R G T A R G(r)}{R O R G R O S S(r)},
$$

where $R R G \_R O R G(r)$ denotes the required rate of growth in the rate of return, and $L A M B R O R G(r)$ a coefficient of adjustment. Differentiating, we obtain

$R R G \_R O R G$

$L A M B R O R G$

$$
\operatorname{rrg} \_r o r g(r)=L A M B R O R G(r) *[\operatorname{rorgt}(r)-\operatorname{rorga}(r)],
$$

where $r r g \_r o r g(r)$ denotes (absolute) change in the required rate of growth in the rate of return in region $r$, and rorgt $(r)$, percentage change in the target rate of return. Note that this is not the final form of the equation; we present that in subsection 5.3 below, following further theoretical development.

Referring back to equation (36), we note that the target rate of return includes both region-specific components $\operatorname{RISK}(r)$ and $R D E P(r)$ and a region-generic component $R O R C O M M$. In the present context there is a further possible region-generic component, a world-wide drift in rates of return such as to accommodate the global level of investment. We do not represent all these components explicitly in the model, but instead write simply

$$
R O R G T A R G(r)=S D R O R T W O R L D+S D R O R T A R G(r),
$$

where SDRORTWORLD denotes a region-generic component in the target rate of return, and SDRORTARG $(r)$ a component specific to region $r$. Differentiating, we obtain

$$
\operatorname{DRORT}(r)=S D R O R T W+\operatorname{SDRORT}(r),
$$

where DRORT $(r)$ denotes the absolute change in the target rate of return, SDRORTW a region-generic shift, and $S D R O R T(r)$ a region-specific shift. We use here the absolute rather than the percentage change form for the target rate, to ensure that any world-wide shift SDRORTW leads to equal percentage-point changes in rates of return in different regions; equivalently, to ensure that any cross-region differentials are maintained in percentage point rather than percentage terms (so, for example, we might maintain a risk premium of two percentage points, but not a risk premium equivalent to 20 per cent of the rate of return). We have then

$$
\operatorname{DRORT}(r)=S D R O R T W+\operatorname{SDRORT}(r)
$$


or in TABLO code,

Equation E_DRORT \#equilibrium condition for rate of return\#
$(\operatorname{all}, r, R E G)$
$\operatorname{DRORT}(r)=\operatorname{SDRORTW}+\operatorname{SDRORT}(r)$

We relate the absolute-change variable $D R O R T$ to the percentage-change variable rorgt with the equation

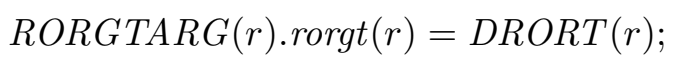

in the code,

Equation E_rorgt \#identity for target gross rate of return\#
$(\operatorname{all}, r, R E G)$
$\operatorname{RORGTARG}(r) * \operatorname{rorgt}(r)=\operatorname{DRORT}(r)$

\subsection{The expected rate of growth in the rate of return}

Having determined above (subsection 5.1) the required rate of growth in the rate of return, we now relate this to the level of investment, through an equation linking the expected rate of growth in the rate of return to investment, and a condition that the expected rate should be equal to the required rate.

This brings us to one of the central elements of the investment theory, the expected rate of return schedule. Investors understand that, the higher the level of the capital stock at any given time, the lower the rate of return at that time. Accordingly, the rate of return expected to prevail at any future time depends on the capital stock at that time. Consequently, the expected rate of growth in the rate of return depends on the rate of growth in the capital stock; or, equivalently, on the level of investment.

We describe investors' understanding of the investment environment through a rate of return schedule, relating the expected rate of return to the size of the capital stock:

$$
\frac{R O R G E X P(r)}{R O R G R E F(r)}=\left[\frac{Q K(r)}{Q K F(r)}\right]^{-R O R G F L E X(r)},
$$

where RORGEXP $(r)$ denotes the expected gross rate of return and RORGFLEX $(r)$ a positive parameter, representing the absolute magnitude of the elasticity of the expected rate of return with respect to the size of the capital stock. RORGREF( $r)$ denotes a reference rate of return in region $r$, and $Q K F(r)$ a reference capital stock. Investors

RORGEXP RORGFLEX

RORGREF

QKF expect that if the actual capital stock $Q K$ is equal to the reference stock $Q K F$, then the rate of return will be equal to the reference rate $R O R G R E F$. If the capital stock 
exceeds the reference stock, the expected rate of return is less than the reference rate; if the capital stock is less than the reference stock, the expected rate is greater than the reference rate.

In dealing with expectations, as in equation (43), there are two relevant times: the time at which the expectations are held, and the time to which they refer. We call these respectively the expectation time and the realization time. So for example, in describing an investor in 2000 holding an expectation about the rate of return in 2005, the expectation time is 2000 and the realization time 2005.

In the theory underlying the investment module, expectation time is always just the current time TIME for the model. For example, if the model represents the state of the world economy in the year 2000, then expectations time is 2000. Realization time TREAL however may be either the current or some future time. In the model itself, as opposed to the underlying theory, expectation time and realization time are always equal to the current time; so in the model equations TREAL would be redundant, and we use only the current time TIME.

To complete our description of investor expectations in equation (43), we need to specify how the reference rate of return and the reference capital stock depend on realization time. We postulate that the reference rate of return is independent of realization time, while the reference capital stock grows at some normal rate $\operatorname{KHAT}(r)$ :

$$
Q K F(r)=Q K O(r) e^{K H A T(r) T R E A L},
$$

where $Q K O(r)$ denotes the reference capital stock at some base time TREAL $=0$. Under this treatment, the normal rate of growth $K H A T(r)$ is the rate at which the capital stock can grow without (as investors expect) affecting the rate of return. If the capital stock grows at a rate greater than $K H A T(r)$, investors expect rates of return to decline through time; if the capital stock grows at less than $K H A T(r)$, investors expect rates of return to fall.

The specification of expectations in equations (43) and (44), while simple, is intended to approximate the actual investment schedule. In particular, it allows a range between zero and infinity to the gross rate of return RORGROSS $(r)$. This allows, realistically, that the net rate of return may sometimes be negative. Whether the specification is locally model-consistent depends on the setting of the normal growth rate $K H A T(r)$ and the elasticity RORGFLEX $(r)$. As discussed in subsection 5.4, we allow modelconsistent adjustment of $K H A T(r)$. RORGFLEX $(r)$, however, is fixed; we can set it initially at a locally model-consistent value, but through a simulation or series of projections, it typically becomes more or less inconsistent. This is undesirable, but also 
unavoidable without a considerable increase in the complexity of the theory.

To find the expected rate of growth in the rate of return, we differentiate equation (43) with respect to realization time, substituting for $Q K F(r)$ from equation (44), obtaining

$$
E R G_{-} R O R G(r)=-R O R G F L E X(r)\left(R G_{-} Q K(r)-K H A T(r)\right),
$$

where $E R G \_R O R G(r)$ denotes the expected rate of growth in the rate of return in region $r$, and $R G_{-} Q K(r)$ the rate of growth in the capital stock. Now the rate of growth in the capital stock,

$$
\begin{aligned}
R G_{-} Q K(r) & =\frac{d Q K(r) / d \text { TIME }}{Q K(r)} \\
& =\frac{Q C G D S(r)-R D E P(r) Q K(r)}{Q K(r)} \\
& =\frac{Q C G D S(r)}{Q K(r)}-\operatorname{RDEP}(r),
\end{aligned}
$$

where $Q C G D S(r)$ denotes the level of investment in region $r$. Substituting into equation (45), we obtain

$$
E R G \_R O R G(r)=-R O R G F L E X(r)\left(\frac{Q C G D S(r)}{Q K(r)}-R D E P(r)-K H A T(r)\right) .
$$

Totally differentiating, we obtain

$$
e_{\text {erg_rorg }}(r)=-\operatorname{RORGFLEX}(r)[\operatorname{IKRATIO}(r)(q c g d s(r)-q k(r))-D K H A T(r)] \text {, }
$$

where erg_rorg $(r)$ denotes absolute change in the expected rate of growth in the rate of return in region $r$, IKRATIO $(r)$, the ratio $Q C G D S(r) / Q K(r)$ of gross investment to the capital stock, $q c g d s(r)$, percentage change in investment, and $D K H A T(r)$, absolute change in the normal rate of growth in the capital stock. Then, in the model we have:

$E R G \_R O R G$ $R G_{-} Q K$

$Q C G D S$

erg _rorg IKRATIO $q c g d s$ DKHAT

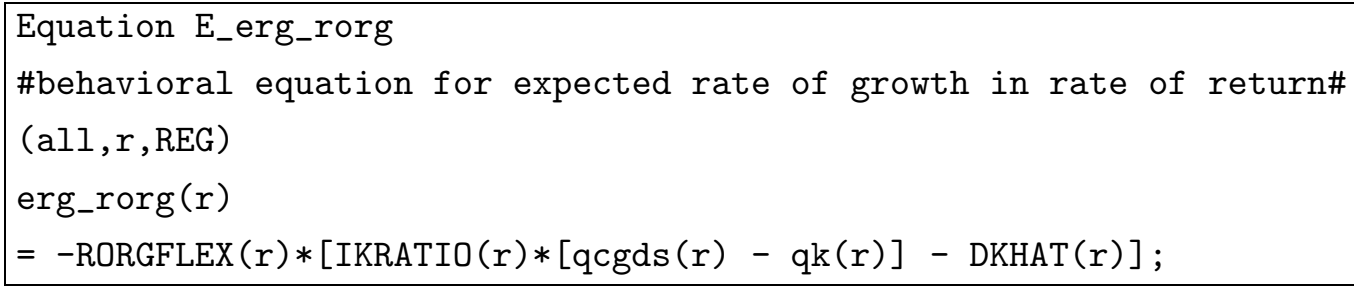

As equation (47) shows, the expected rate of growth in the rate of return varies inversely with the level of investment. Then the level of investment is given implicitly 
by the condition that the expected rate of growth be equal to the required rate,

$$
E R G \_R O R G(r)=R R G \_R O R G(r) .
$$

We depict some aspects of the investment theory in figure 3. Each point in the figure represents a (capital stock, rate of return) pair $(Q K, R)$. The curve $(\mathrm{A})$ represents the expected rate of return schedule for realization time equal to expectation time; it is downward sloping, with slope related to the elasticity RORGFLEX, a vertical asymptote at $Q K=0$, and a horizontal asymptote at $R=0$. It passes through the point $(Q K, R O R G R O S S)$ representing the current capital stock and rate of return, and also through the reference point ( $Q K F, R O R G R E F)$; the reference point adjusts implicitly to allow this.

For a realization time greater than the expectation time, the curve would be similar to (a) but dilated about the vertical axis; assuming a positive normal growth rate, the curve would dilate rightward as realization time increased.

As we have drawn the figure, the actual rate of return RORGROSS exceeds the target rate RORGTARG. From equation (39), this implies that the required rate of growth in the rate of return is negative; on the diagram, this implies some required downward vertical speed. Inverting equation (46) and equating the required rate of return to the expected rate, we find the required level of investment,

$$
Q C G D S(r)=Q K(r)\left[R D E P(r)+K H A T(r)-R O R G F L E X(r) . E R G \_R O R G(r)\right] .
$$

Here $Q K(r) \cdot R D E P(r)$ is the investment level required to maintain the capital stock $Q K(r)$ at its current level, $Q K(r) . K H A T(r)$ the further investment required to keep pace with the rightward dilation of the rate of return curve $(\mathrm{A})$, and $Q K(r)$ .RORGFLEX $(r)$.ERG_RORG(r) the further investment required to maintain the required vertical speed down the curve.

\subsection{Adaptive expectations}

In practice, the investment theory as presented to this point in equations (40), (47), and (48) has a significant disadvantage. Using information in the benchmark data, we can calculate the actual rate of return RORGROSS $(r)$ in the initial year. The rate of return and the equations of the model allow us to determine the level of investment $Q C G D S(r)$. However, the benchmark data also specifies the level of investment. This level, in general, will be inconsistent with the level calculated with the theory.

Consider, for example, the region with the highest rate of return in the data base. 
In this region the actual rate of return exceeds the target rate, so the required rate of growth in the rate of return $R R G_{-} R O R G(r)$ is negative. This, in turn, implies that the normal rate of growth in the capital stock $K H A T(r)$, and investment QCGDS(r) should be high. However, it may be that the level of investment recorded in the data base is not particularly high. In this case, theory and data are inconsistent. We could modify the data by lowering the rate of return, or we could generalize the theory to achieve such an outcome.

We can resolve this inconsistency by modifying either the data or the theory. One approach to modifying the data involves equalizing rates of return across countries in the data base. This conflicts with one of our objectives for the dynamic model, that it should work with data bases that conform closely to observed statistics, rather than requiring a heavily recalibrated or stylized data base. Another approach would be to account for investment level anomalies through risk premia; we can do this readily in the data base, without touching the flows data, by adjusting the target rates. This option is sometimes appealing; we do not wish however to force it on users. Rather we recognize that reality is under no obligation to respect our (or any other) investment theory, and that for a multitude of reasons, observed investment levels will surely differ from any theoretical prediction. We therefore extend the theory so that it does not prescribe investment levels, but accommodates the observed investment levels over the short run, while still maintaining the old theory's long-run properties.

We achieve the desired relaxation by letting investors react to expected rather than actual rates of return. With this approach we can account for any observed level of investment, by setting the expected rate of return so as to warrant that investment level. At the same time, by incorporating an adjustment mechanism that draws the expected rate of return gradually toward the actual rate, we retain the long-run properties of the simpler theory, including long-run equalization of rates of return. Furthermore, this way of accounting for observed investment levels has some theoretical appeal.

Investment is undertaken with the expectation of deriving returns over some period of time. Thus, investors are concerned not only with the rate of return at the moment of purchasing an asset, but also with the rate of return throughout its life. Investors' expectations are also "sticky" or "sluggish". When the observed rate of return changes, investors are unsure whether this change is transient or permanent. They adjust their expectations of future rates of return only with a lag. At first investors make a small adjustment, then if the change in the actual rate persists, they make further changes in expectations, until eventually the expected rate conforms to the observed rate.

Earlier (subsection 5.1), we represented investors' reactions to current returns 
through equation (40):

$$
\operatorname{rrg}_{-} \operatorname{rorg}(r)=L A M B R O R G(r) *[\operatorname{rorgt}(r)-\operatorname{rorga}(r)] \text {. }
$$

To let investors react to the expected rate of return rather than the actual rate, we replace the actual rate of return variable rorga with the expected rate variable rorge. At the same time, we enforce the condition that the expected rate of growth in the rate of return be equal to the required rate, by replacing the required rate rrg_rorg $_{\text {with }}$ the expected rate erg_rorg. This gives us the final form of the equation,

$$
\operatorname{erg} \_ \text {rorg }(r)=L A M B R O R G(r) *[\operatorname{rorgt}(r)-\operatorname{rorge}(r)]
$$

In the model, we implement this as:

$$
\begin{aligned}
& \text { Equation E_erg_rorg \# rule for investment \# (all,r,REG) } \\
& \operatorname{erg} \_r o r g(r)=\operatorname{LAMBRORG}(r) *[\operatorname{rorgt}(r)-\operatorname{rorge}(r)]
\end{aligned}
$$

We now need to specify an error correction mechanism bringing the expected rate rorge closer through time to the actual rate rorga. We recall equation (43) for the expected rate of return schedule,

$$
\frac{R O R G E X P(r)}{R O R G R E F(r)}=\left[\frac{Q K(r)}{Q K F(r)}\right]^{-\operatorname{RORGFLEX}(r)},
$$

and note a few points:

- Even before the theoretical extension introduced in this subsection, we already have a concept of an expected rate of return.

- Previously, however, the expected rate of return schedule was such that, at the current capital stock and the current time, the expected rate of return was equal to the actual current rate of return. Now we allow that the expected current rate of return may differ from the actual rate.

- As specified by the expected rate of return schedule, the expected rate of return is conditional on the capital stock, and also on realization time. This rules out a simple adjustment rule for the expected rate of return, such as

$$
\operatorname{rorge}(r)=100 . \operatorname{LAMBRORGE}(r)\left[\log \frac{\operatorname{rorga}(r)}{\operatorname{rorge}(r)}\right] \text { time. }
$$

This would represent investors as perversely ignoring the effects of investment and economic growth on the rate of return. Rather than an adjustment rule for the 
rate of return itself, we need an adjustment rule for the rate of return schedule, shifting so that through time the expected current rate of return draws closer to the actual current rate.

- From equations (43) and (44), we note that the position of the rate of return schedule is given by the reference rate of return, RORGREF $(r)$, and the base time value of the reference capital stock, $Q K O(r)$.

To specify an error correction mechanism for the rate of return schedule, we define the warranted reference rate of return, RORGFWARR $(r)$, as value for the reference

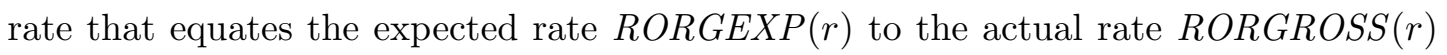
in equation (43). Then the warranted reference rate of return is given implicitly by the equation

$$
\frac{R O R G R O S S(r)}{R O R G F W A R R(r)}=\left[\frac{Q K(r)}{Q K F(r)}\right]^{-R O R G F L E X(r)} .
$$

From equations (43) and (50), we have

$$
\frac{R O R G F W A R R(r)}{R O R G R E F(r)}=\frac{R O R G R O S S(r)}{R O R G E X P(r)} .
$$

We postulate an error correction process, through which the reference rate of return draws closer through time to the warranted rate:

$$
\operatorname{rorgf}(r)=100 . L A M B R O R G E(r)\left[\log \frac{R O R G F W A R R(r)}{R O R G R E F(r)}\right] \text { time, }
$$

where $\operatorname{rorgf}(r)$ denotes percentage change in the reference rate of return, and $L A M B R O R G E(r)$ an adjustment coefficient. Substituting from equation (51), we obtain

$$
\begin{aligned}
\operatorname{rorgf}(r) & =-100 \cdot L A M B R O R G E(r)\left[\log \frac{\operatorname{RORGEXP}(r)}{\operatorname{RORGROSS}(r)}\right] \text { time } \\
& =-100 \cdot \operatorname{LAMBRORGE}(r) \cdot \operatorname{ERRRORG(r).time}
\end{aligned}
$$

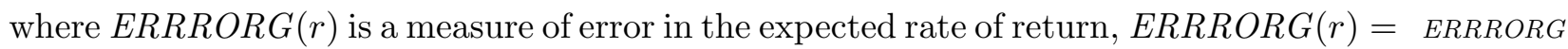
$\log ($ RORGEXP $(r) / R O R G R O S S(r))$.

Having specified this error correction mechanism for the expected rate of return schedule, we can now derive the error-correcting equation for the expected rate of return itself. Recalling equation (44)

$$
Q K F(r)=Q K O(r) e^{K H A T(r) T I M E}
$$


we substitute into equation (43), obtaining

$$
\frac{R O R G E X P(r)}{R O R G R E F(r)}=\left[\frac{Q K(r)}{Q K O(r) e^{K H A T(r) T I M E}}\right]^{-R O R G F L E X(r)} .
$$

At this point, we add one final feature. For various reasons, users may sometimes wish to intervene in the expectations-setting process. They may wish to add some additional shock to the expected rate of return, or they wish to deactivate the expectations rule, so as for example to set the investment level directly. To allow this, we add a shift factor SRORGEXP $(r)$ to the expected rate equation. This normally is exogenous and zero; it may be given a non-zero value to add exogenous shocks to the expectationsetting process, or endogenized to disable the expectations rule so that, for example, the investment level may be set directly. This gives us the final form for the levels equation,

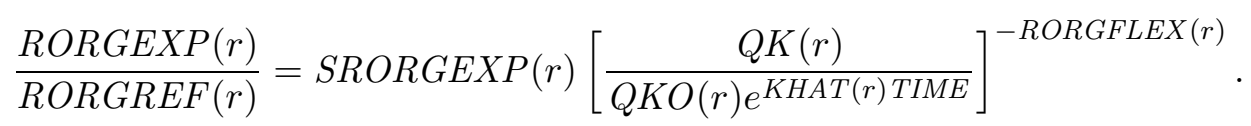

Differentiating, we obtain

$$
\operatorname{rorge}(r)=\operatorname{rorgf}(r)-\operatorname{RORGFLEX}(r)(q k(r)-100 . K H A T(r) . t i m e)+\operatorname{srorge}(r),
$$

where srorge $(r)$ denotes percentage change in the expected rate shift factor. Substitutsrorge ing for rorgf from equation (52), we obtain

$$
\begin{aligned}
\operatorname{rorge}(r)= & -\operatorname{RORGFLEX}(r)(q k(r)-100 . \operatorname{KHAT}(r) . \text { time }) \\
& -100 . \operatorname{LAMBRORGE}(r) . \operatorname{ERRRORG}(r) . \text { time } \\
& +\operatorname{srorge}(r) .
\end{aligned}
$$

This equation shows three sources of change in the expected rate of return: divergence between the actual rate of growth in the capital stock, $q k(r) /[100 . t i m e]$, and the normal growth rate $K H A T(r)$; a correction for the observed error in the expected rate; and an exogenous shift factor. We implement this in the model as

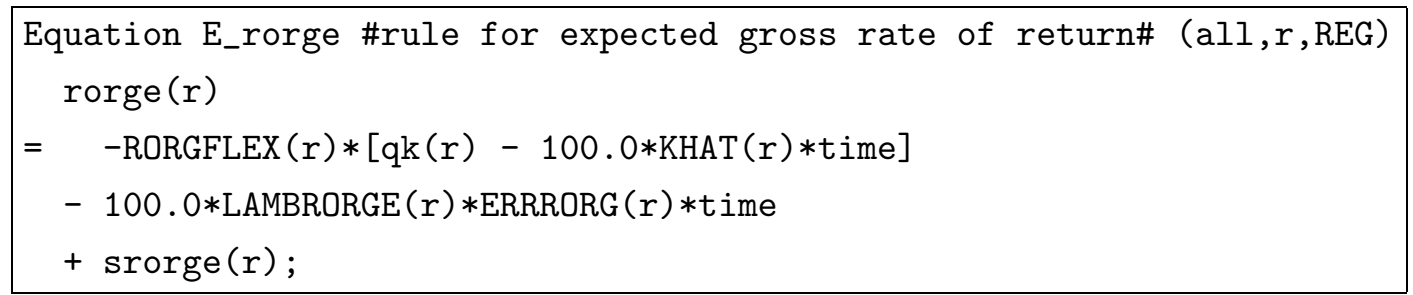




\subsection{The normal rate of growth in the capital stock}

As noted in subsection 5.2, whether the expected growth rate $E R G \_R O R G$ is modelconsistent depends in part on the normal growth rate KHAT. In some early versions of the model, we treated KHAT as a fixed parameter, and calibrated it before each base case projection (that is, the series of projections forming the base case for some collection of experiments with the model), to ensure that it was consistent with the longrun behavior of the model. This had two disadvantages. It forced us to calibrate the parameter anew for each base-case projection, and this was somewhat onerous. Also, it held KHAT constant within each projection, and this was not always appropriate. For example, it would not be appropriate to a projection involving slow technological progress through the 1980s, but faster progress through the 1990s. We could avoid this by setting several different KHAT values for different periods within the projection, but that involved yet more calibration simulations.

To avoid these problems, we now treat the normal growth rate KHAT as an updateable coefficient within the model, and provide an adjustment mechanism to bring it towards a model-consistent value through the course of a simulation. We postulate an adjustment mechanism

$$
\text { DKHAT }(r)=\text { 100.LAMBKHAT }(r)(K H A P P(r)-K H A T(r)) \text { time, }
$$

where $L A M B K H A T(r)$ denotes a coefficient of adjustment, and $K H A P P(r)$ the apparent current normal growth rate in region $r$.

By the apparent current normal growth rate, we mean the normal growth rate implied by current changes in the capital stock and the rate of return, and by the assumed elasticity RORGFLEX. If the rate of return is currently constant, then it appears that the capital stock is growing at the normal rate, so the apparent normal rate is equal to the actual rate. If the rate of return is rising, then the apparent normal rate is greater than the actual rate; if the rate of return is falling, the apparent normal rate is lower than the actual rate.

To calculate the apparent normal rate, we return to the expected investment schedule equation (43), assume that it agrees with the actual schedule, and solve for the apparent value $K H A P P$ of the normal growth rate $K H A T$. We thus obtain

$$
\operatorname{KHAPP}(r)=R O R G F L E X(r)^{-1} A R G_{-} R O R G(r)+\frac{Q C G D S(r)}{Q K(r)}-R D E P(r) .
$$

This shows that the apparent normal growth rate $K H A P P(r)$ is equal to the actual growth rate $Q C G D S(r) / Q K(r)-R D E P(r)$, plus an adjustment $R O R G F L E X(r)^{-1}$ 
$A R G_{-} R O R G(r)$ for current growth in the rate of return. Substituting into equation (54), we obtain

$$
\begin{aligned}
& \text { DKHAT }(r)= \\
& \text { 100.LAMBKHAT }(r) \\
& \quad\left(\text { RORGFLEX }(r)^{-1} \text { ARG_RORG }(r)+\frac{Q C G D S(r)}{Q K(r)}-\operatorname{RDEP}(r)-K H A T(r)\right) \\
& \quad \text { time. }
\end{aligned}
$$

Now adapting equation (7), we have

$$
100\left(\frac{Q C G D S(r)}{Q K(r)}-R D E P(r)\right) \text { time }=q k(r) .
$$

Also, by definition of $A R G_{-} R O R G(r)$ we have

$$
\text { 100.ARG_RORG(r) time }=\text { rorga }(r) \text {. }
$$

Substituting into equation (55), we obtain

$$
\begin{aligned}
\operatorname{DKHAT}(r)= & \operatorname{LAMBKHAT}(r) \\
& \left(\operatorname{RORGFLEX}(r)^{-1} \operatorname{rorga}(r)+q k(r)-100 . \operatorname{KHAT}(r) . \text { time }\right) .
\end{aligned}
$$

Translating into TABLO code, we have in the model

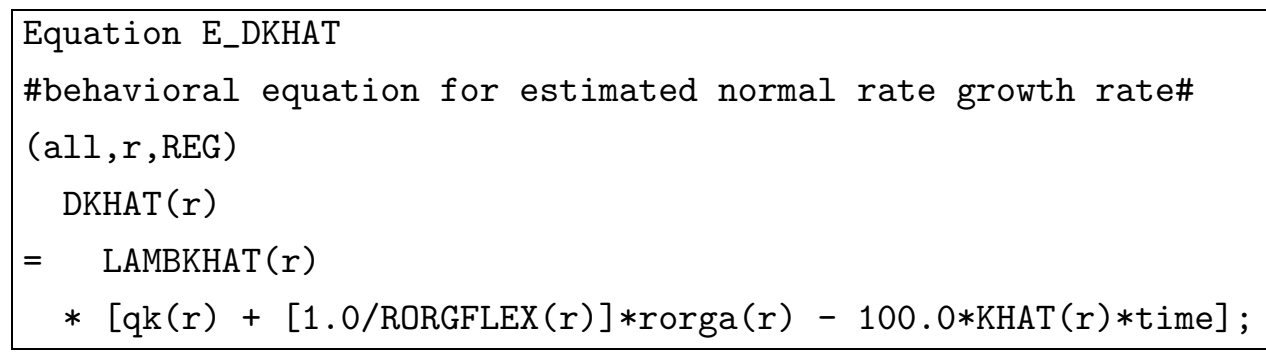

Figure 4 shows two rate-of-return curves: the expected rate curve (E), passing through the current capital stock and expected current rate of return, ( $Q K$, RORGEXP); and the warranted curve (A), passing through the current capital stock and actual current rate of return, (QK, RORGROSS). As before, the expected investment curve dilates rightward through time at a rate given by the normal rate of growth in the capital stock KHAT (or leftward, if KHAT is negative). But now it also dilates vertically, so as to draw closer to the warranted curve (A). Now the shape of the curve is such that any vertical dilation is equivalent to a horizontal dilation, and vice-versa; 
specifically, a vertical dilation by a factor $V$ is equivalent to a horizontal dilation by a factor $V^{R O R G F L E X}$. So we may say simply that the curve dilates inward or outward, at a rate depending on the normal growth rate $K H A T$, but adjusted so as to draw closer to the warranted curve $(\mathrm{A})$.

As the expected rate curve dilates outward, so too does the warranted rate curve, at a rate described by the apparent normal growth rate $K H A P P$.

If the error in expectations is zero (RORGEXP $(r)=\operatorname{RORGROSS}(r))$ and the expected normal growth rate KHAT agrees with the apparent rate KHAPP, then the expected rate and warranted rate curves (E) and (A) coincide, and furthermore, dilate outward together at the same rate so as to remain coincident.

If the error in expectations is zero (RORGEXP $(r)=R O R G R O S S(r))$, but the apparent normal growth rate KHAPP exceeds the expected normal growth rate KHAT, then the expected rate curve (E) and the warranted rate curve (A) are initially coincident, but the warranted rate curve dilates outward faster than the expected rate curve. Through the normal rate adjustment process, the normal rate accelerates toward the apparent rate, pushing the velocity of the expected rate curve closer to that of the warranted rate curve; while the rate of return adjustment process pushes the position of the expected rate curve closer to that of the warranted rate curve.

If the expected normal growth rate $K H A T$ agrees with the apparent growth rate $K H A P P$, but the expected rate of return RORGEXP exceeds the actual rate RORGROSS, then the expected rate curve (E) lies outside the warranted rate curve (A). Then the expected rate curve dilates outward at less than the normal rate, allowing the warranted rate curve to catch up with it.

\subsection{Summary}

Equations (49), (47), (56), and (53), shown in Table 1, comprise the investment theory of adaptive expectations and jointly determine the forward-sloping regional supply of investment funds. With this set of equations, there is perfect capital mobility only over the long run as regional rates of return gradually adjust towards a common target rate.

Equation (53) both determines the expected rate rorge and (in figure 4) governs the position of the expected rate curve (E). It lets the expected rate curve (E) dilate outward at a rate governed partly by equation (56) and partly by a catch-up component drawing toward the warranted rate curve (A). Equation (56) coordinates the movements of curves (A) and (E) so that (abstracting from the catch-up effect) their velocities draw together. Equation (49) specifies the required rate of growth in the expected rate of return - the required vertical velocity of the point $(Q K, R O R G E X P)$ in figure 4 ; and 
equation (47) translates this into a required level of investment, or horizontal velocity within the figure, given the vertical velocity and the requirement that the point lie on the expected rate curve (E). Thus, equations (49), (47), (56), and (53) determine regional investment, and, via the accumulation equation (10), regional capital stocks in GTAP-Dyn.

To illustrate the disequilibrium nature of the adjustment mechanism in this model, let us assume initially an equality between the actual, expected, and target rates of return. This equality implies that the actual and expected schedules overlap and move together in response to changes in the normal rate of growth in the capital stock $K H A T(r)$. If there is a positive shock to productivity, the actual rate of return increases and the warranted rate schedule (A) moves to the right of the expected rate schedule (E). The model detects the acceleration in economic growth via equation (56) in the initial period of the shock, which leads to an increase in regional investment via equation (47). Next period, a further increase in the expected normal growth rate $K H A T(r)$ leads to a further rise in regional investment. Graphically, this is represented by an outward dilation of the expected rate curve. In addition, via the second term of equation (53), investors realize that the expected rate of return is lower than the actual rate of return. This leads both to a further outward dilation of the expected rate curve toward the warranted rate curve, and, through equation (49), a decrease in the required rate of growth in the rate of return, $R R G_{-} R O R G$. Equation (47) translates this into a rightward movement qcgds along the expected rate curve.

Taking these four equations together, together with the equations (41) and (42) for rorgt, we may regard them as an equation subsystem. With a normal closure, the subsystem takes as given the variables $q k, S D R O R T$, srorge, and time, and one degree of freedom of $q c g d s$ ( $q c g d s$ is constrained by the requirement that the money value of world investment must equal world saving). It determines the variables $q c g d s$ and SDRORTW. The variables DKHAT, DRORT, erg_rorg, rorge, and rorgt are internal to the subsystem.

In its relations with the rest of the equation system, this subsystem has some notable features. It may be surprising that the capital stock $q k(r)$ helps to determine the investment level. Referring back to the derivation of equation (47), we see that achieving a given expected rate of growth in the rate of return entails achieving a certain rate of growth in the capital stock; the level of investment required to achieve that rate of growth depends on the size of the capital stock. The capital stock thus serves as a scaling factor for investment.

Equally notable is the absence of certain links from the equation system. We expect the actual rate of return to affect the expected rate, yet in the expected rate of 
return equation (53) the variable rorga $(r)$ does not affect rorge $(r)$. Equally, we expect investment to affect the capital stock, yet in the capital accumulation equation (10), the variable $q c g d s(r)$ does not affect $q k(r)$. The explanation is that these links do exist in the theoretical structure, but through coefficients rather than variables. The level

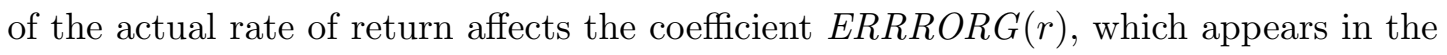
expected rate of return equation and affects the variable rorge $(r)$. Similarly, the level of gross investment affects the coefficient $\operatorname{NETINV}(r)$, which appears in the capital accumulation equation and affects the variable $q k(r)$.

\subsection{Alternative investment determination}

In some simulations, the user may wish to disable the investment theory described in the preceding subsections and instead impose specific investment targets. For example, she may wish to use investment forecasts from macroeconomic models, or to model sudden (perhaps dramatic) fluctuations in investment, such as those observed in the Asian crisis.

Imposing investment targets on all regions is harder than it may at first seem. Through the identity that world saving is equal to world investment, it would implicitly impose a target on world saving. To accommodate that, the user would need to change the treatment of saving in the closure. In this section we consider a more limited objective, imposing targets on regional shares in world investment, while allowing the usual saving theory to determine its level.

To enable this, we use an equation

$$
Q C G D S(r)=S Q C G D S R E G(r) . S Q C G D S W O R L D
$$

representing investment in region $r$ as the product of a region-specific factor

$S Q C G D S R E G(r)$ and a region-generic factor $S Q C G D S W O R L D$. Differentiating, we obtain

$$
q \operatorname{cgds}(r)=\operatorname{sqcgdsreg}(r)+\operatorname{sqcgdsworld},
$$

where sqcgdsreg $(r)$ and sqcgdsworld denote percentage changes in SQCGDSREG $(r)$ and SQCGDSWORLD. In the TABLO code, we write

SQCGDSREG $S Q C G D S W O R L D$

sqcgdsreg sqcgdsworld

Normally sqcgdsworld is exogenous and sqcgdsreg $(r)$ endogenous, so that the GTAPDyn investment theory determines $q c g d s(r)$ and equation (57) determines sqcgdsreg $(r)$. 
But when we wish to target the regional allocation of investment, we exogenize sqcgdsreg and endogenize either srorge or SDRORT. At the same time, we exogenize SDRORTW and endogenize sqcgdsworld, letting sqcgdsworld adjust so that global investment remains equal to global saving.

If we wish to target the investment allocation in all periods, it does not matter whether we endogenize srorge or SDRORT. If however we wish to target it only in earlier periods, but let the investment theory drive it in later periods, then the choice of variable does matter.

If in the earlier periods we endogenize srorge, the model achieves the investment targets by adjusting expected rates of return. In the later periods, with srorge exogenous, the expected rates converge toward the actual rates according to the usual GTAP-Dyn theory. So under this treatment, the imposed investment allocation is transient.

If however in the earlier periods we endogenize SDRORT, the model achieves the investment targets by adjusting target rates of return. In the later periods, with $S D R O R T$ exogenous, the differentials in the target rates remain in place, unless and until we shock them back toward equality. So under this treatment, the imposed investment allocation is persistent.

\section{$6 \quad$ Properties and problems}

Having completed the presentation of the GTAP-Dyn theoretical structure, we now discuss some properties of the system, and issues arising in using it.

- existence and stability of long-run equilibrium,

- cumulative and comparative dynamic results,

- path dependence,

- one-way relations,

- capital account volatility and the propensity to save.

\subsection{Long-run equilibrium}

In the GTAP-Dyn investment theory (section 5), expected, target, and actual rates of return may all differ over the short run. In long-run equilibrium, these three rates are all equal, and constant over time, as is also the normal growth rate for the capital stock:

$$
\operatorname{RORGEXP}(r)=\operatorname{RORGTARG}(r)=\operatorname{RORGROSS}(r), \forall r
$$




$$
\begin{aligned}
\operatorname{ROR} \dot{G E X P}(r) & =\operatorname{RORG} \operatorname{TARG}(r)=\operatorname{ROR} \dot{G} R O S S(r)=0, \forall r \\
\operatorname{KHAT}(r) & =0, \operatorname{DKHAT}(r)=0, \forall r .
\end{aligned}
$$

These conditions imply in turn a constant investment-capital ratio. They are the same conditions characterizing the equilibrium solution of a multi-region q-investment model with convex adjustment costs.

Ianchovichina (1998) demonstrates the existence and stability of the long-run equilibrium. Here we provide a numerical illustration. We use a three-region aggregation of the version 3 GTAP data base (McDougall 1997) featuring the United States (USA), the European Union (E_U), and all other regions aggregated into a rest-ofworld region (ROW). The initial data (1992) reveal regional differences in rates of return, RORGROSS (r) (Figure 5), normal rates of growth in capital KHAT $(r)$ (Figure 7), investment-capital ratios (Figure 8), as well as sizable errors in expectations ERRRORG(r) (Figure 6). In short, the benchmark data depict a world in disequilibrium.

We test the long run properties of the model over a hundred year period. The simulation represents the changes in the three economies occurring solely due to the passage of time. It depicts the movement from the initial disequilibrium state towards a long-run equilibrium. For simplicity, we assume zero regional risk premia.

Figure 6 suggests that in 1992 investors underestimated returns to capital in the United States and the rest of the world and overestimated returns to capital in the European Union. As investors realize their errors in predicting these returns, they adjust their expectations in an upward direction in the case of the United States and the rest-of-world region, and in a downward direction in the case of the European Union (via equation (53)). As a result, investment in the United States and the rest of the world increases, while investment in the European Union declines (via equations (49) and (47)). It takes approximately 12 years for the model to eliminate errors in expectations (Figure 6) and inter-regional differences in rates of return (equilibrium condition (58), Figure 5). However, since $K H A T(r)$ is neither zero nor a constant in 2004, this is only a temporary equilibrium. Positive and nonconstant KHAT(r) (Figure 7) implies that the expected investment schedule (43) will overshoot the warranted one (50), and over time will start moving back. We observe this type of oscillating behavior on Figures 5, 6, 7, and 8 around 2004. Only after further reduction in KHAT via equation (56), leading to a reduction in the investment-capital ratio via equation (47), will the model permanently eliminate errors in expectations and differences in inter-regional rates of return.

Figure 5 shows the convergence of the regional rates of return $\operatorname{RORGROSS}(r)$ to- 


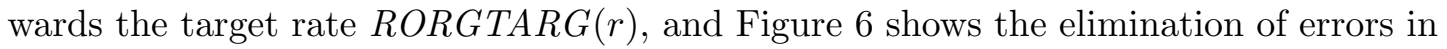
expectations ERRRORG(r) over time. Figure 7 displays the normal rate of growth in the capital stock $K H A T(r)$ in its movement towards 0 over the long-run, while Figure 8 demonstrates the process of adjustment towards constant investment-capital ratios. The three figures suggest that the stability conditions of the model are satisfied over time.

\subsection{Cumulative and comparative dynamic results}

GTAP-Dyn is designed as a recursive dynamic model. To obtain projections through time, you run a sequence of simulations, one for each time period in the projection. To obtain comparative dynamic results, you run two sequences of simulations, one representing a base case projection and the other representing a variant projection. From the period-by-period results, you then calculate cumulative results for each projection. Finally you difference the two series of cumulative results to obtain comparative dynamic results.

The formulas used for cumulating and differencing are different for the different kinds of variable distinguished in GEMPACK, change and percentage change. For a change variable $d V$, the cumulative change over two periods 1 and 2,

$$
d V_{02}=d V_{01}+d V_{12}
$$

where the subscript 01 denotes changes between the start and end of period 1 , and 12 , changes between the end of period 1 and the end of period 2. For a percentage change variable $v$, we have a more complex formula,

$$
v_{02}=100\left[\left(1+\frac{v_{01}}{100}\right)\left(1+\frac{v_{12}}{100}\right)-1\right] .
$$

This procedure works for most of the variables in the model, but not for all. In particular, it does not work for the equivalent variation, $E V(r)$, and associated variables. The problem is that the variable is defined so that, in say the first period, the equivalent variation variable is

$$
E V_{01}=E\left(U_{1}, \mathbf{P}_{\mathbf{0}}\right)-E\left(U_{0}, \mathbf{P}_{\mathbf{0}}\right)
$$

where $E$ is the expenditure function, $U$, utility, $\mathbf{P}$, prices, and the subscripts 0 and 1 refer to values at the beginning and end of the first period. In the second period, we 
have

$$
E V_{12}=E\left(U_{2}, \mathbf{P}_{\mathbf{1}}\right)-E\left(U_{1}, \mathbf{P}_{\mathbf{1}}\right)
$$

Then the cumulative equivalent variation for the first and second periods,

$$
E V_{02}=E\left(U_{2}, \mathbf{P}_{\mathbf{0}}\right)-E\left(U_{0}, \mathbf{P}_{\mathbf{0}}\right)
$$

but we cannot calculate this from $E V_{01}$ and $E V_{12}$. Thus we cannot calculate valid cumulative results for the equivalent variation; nor, consequently, valid comparative dynamic results. Similarly, we cannot calculate valid comparative dynamic results for the equivalent variation decomposition (Huff and Hertel, 1996).

This does not mean that we cannot obtain comparative dynamic results for equivalent variation; to obtain them however, we need some computational machinery beyond the cumulating and differencing procedures used for other variables.

\subsection{Path dependence}

GTAP-Dyn is inherently a path-dependent model. That is, in GTAP-Dyn, the effects of changes in exogenous variables depend not only on the overall changes in but also on the paths followed by, the exogenous variables. When GTAP-Dyn is used as a dynamic model - when the time variable time is shocked - this means that the effects of economic shocks depend not only on the size but also on the timing of the shocks.

Path dependence is built into the theory in three places: wealth accumulation (subsection 4.3), the partial adjustment treatment of the capital stock (subsection 5.1), and the adaptive expectations treatment of the expected rate of return and the normal growth rate (subsections 5.3 and 5.4).

In the GTAP-Dyn theory, a region's wealth depends on its past history; it cannot be determined from other current variables, such as income. The final level of regional wealth in any simulation depends on the original level, and on the time paths of the exogenous variables within the simulation. For example, technological progress in a given region normally leads to an increase in its wealth; but the increase in wealth is greater if the technological progress occurs mostly near the beginning of the period than if it occurs mostly toward the end. Other path dependencies arise from the lagged adjustment treatment of the capital stock, and from the adaptive expectations treatment of investment.

Similarly, regional capital stocks cannot be inferred from other current variables. There are two reasons for this. Globally, the money value of net physical investment is equal to saving, so the money value of the global capital stock is determined by wealth 
accumulation (and capital gain), not by an equilibrium condition. Also, the distribution of capital across regions is given not by an equilibrium condition but by a partial adjustment process, as described in subsection 5.1. Investors do redistribute capital to equalize rates of return, but only gradually; past shocks therefore have affected the current international distribution of capital more if they occurred in the more distant past, less if they occurred in the more recent past.

Finally, the level of investment depends not on the actual rate of return but on the expected rate. And the expected rate of return cannot be inferred from other current variables, but adjusts toward the actual rate with a lag (as described in subsection 5.3). Here then is yet another adjustment process whose results depend not only on the size of the changes in its inputs, but also on their timing.

Given GTAP-Dyn's objectives, this path dependence must be construed not as a bug but a feature. Indeed, if we should extend GTAP-Dyn to provide a better treatment of short-run dynamics, bringing in more macroeconomic content such as that found in such models as G-CUBED or FAIR, path dependencies will become more pervasive rather than less. In short, path dependence in GTAP-Dyn is here to stay.

Nevertheless (and this is why one might be tempted to construe it as a bug) path dependence imposes some practical inconveniences. It places on the user an onus to represent accurately the time paths of exogenous variables, in circumstances where it would otherwise be unnecessary. Users need to take it into account in several places in their computational strategy.

First, you need to set periods, within the overall projection time interval, to capture sufficient detail about the time profile of the shocks. With the continuous time approach used in GTAP-Dyn, you can run say a tariff reduction scenario over a single ten-year interval and get sensible and meaningful results. If however you want the tariff cuts to be not implemented at an even pace but backloaded, then you need to use several shorter intervals, so that you may specify lower rates of tariff reduction in the earlier intervals, and higher rates in the later intervals.

Second, even if you wish to apply shocks evenly through time, you may wish to avoid long time intervals, if you do not like the rule TABLO uses to distribute shocks between steps. TABLO-generated programs distribute shocks so that the change in the levels variable is the same for all steps (Harrison and Pearson 1998, ch. 4, "GEMSIM and TABLO-generated Programs"). So (to take an extreme example) if you shock a variable by $300 \%$, using a two-step solution procedure, your TABLO-generated program shocks the variable by an amount equivalent to $150 \%$ of the initial level in each step; that is, by $150 \%$ in the first step (going from 1 to 2.5 times the initial level), and $60 \%$ in the second step (going from 2.5 to 4 times the initial level). 
For most percentage change variables, in most applications, a more appealing default assumption is that the percentage change in the variable is constant across steps. For example, it is more natural to assume that the population grows at a constant rate through time (for example, by 1 per cent per year) than that it changes at a constant rate (for example, by 200,000 persons per year). Likewise, in the extreme example given previously, we would typically prefer by default to shock the variable by $100 \%$ in each step, rather than by $150 \%$ in the first step and $60 \%$ in the second. GEMPACK wizards may perhaps know some way to coerce TABLO to use equal percentage changes; none however is apparent from the published documentation.

The shock-splitting rule does not much matter when the shocks are small, but it does matter when they are large. More specifically, it matters when the total shock in a simulation is large, even if the shock is broken up into small pieces in individual steps. One way to work around the problem is to avoid long intervals always, even if all shocks are evenly distributed through time.

Finally, path dependence rules out some common closure-swapping strategies. In GEMPACK, a common expedient is to let the model determine the change in some instrument variable required to achieve a given change in a target variable, by making the (naturally exogenous) instrument variable endogenous, and the (naturally endogenous) target variable exogenous. For example, we may determine the rate of technological progress required to achieve a given improvement in welfare, by endogenizing the technological change variable and exogenizing the welfare variable. If we then run a second simulation, using the natural closure, and shocking the technological change variable according to the results from the first simulation, we get-with a path-independent model - the same results as in the first simulation. We can then investigate the effects of changes in other elements of the scenario, on welfare as on other variables, using the natural closure and the calibrated technological change shock.

With a path-dependent variable this does not work. The trouble is that the path of the technological change variable is different in the two simulations. In the second simulation, technology changes evenly through the simulation interval; in the first, it changes so as to keep GDP moving evenly through the interval. This is liable to affect the simulation results. In GTAP-Dyn, for example, a front-loaded improvement in technology has more effect on end-of-interval wealth than the same total improvement distributed evenly through the interval.

What we need (but, at the time of writing, do not have) for this problem is an automated algorithm for finding the constant rate of growth in an instrument variable (or the constant rates of growth in a set of instrument variables) that achieves given total growth in a target variable (or a set of target variables). Such a tool would be useful 
not only for single-simulation but also for multi-simulation projections. For example, in a projection made up of five two-year simulations, each involving say different tariff shocks, we would like to be able to find the constant rate of technological progress, through the complete ten-year projection interval, required to achieve a given welfare improvement over the interval. Such a multi-simulation facility would be useful even with path-independent models.

\subsection{One-way relations}

A novel emergent feature of GTAP-Dyn, relative to standard GTAP, is the appearance of what we here describe as one-way relations.

In standard GTAP, as perhaps in most GEMPACK-implemented models, if an exogenous variable $A$ affects an endogenous variable $X$, we can swap $A$ and $X$ in the closure, and determine in a simulation the change in $A$ required to bring about a given change in $X$. Of course, this may not work if $X$ is not monotonic in $A$, but it works most of the time (and, of course, it always works for sufficiently small changes in $X$ if $X$ is locally non-stationary in $A$ ). In GTAP-Dyn however it may easily fail. That is, there are relations between variables $A$ and $X$ such that the solution program can determine the change in $X$ arising from a given change in $A$, but not the change in $A$ required to bring about a given change in $X$ - no matter how well-behaved mathematically the relation between $A$ and $X$.

These one-way relations appear when one variable affects another not through the equation system but through data updates. For example, investment of course affects the capital stock; yet the investment variable ( $q c g d s)$ does not appear in the relevant equation (equation 10),

$$
V K(r) \cdot q k(r)=V K(r)[\text { sqkworld }+s q k(r)]+100 \operatorname{NETINV}(r) . \text { time. }
$$

Instead, the equation contains the investment coefficient NETINV. In a single-step simulation, qcgds has no effect on $q k$; in a multi-step simulation, it affects NETINV at each update of the data files, and thereby affects $q k$.

Now consider the effect of a shock to a normally exogenous, investment-related variable, for example, the target rate shift variable SDRORT. In each period, this leads through the investment module, to some change in the investment variable $q c g d s$, But that change in $q c g d s$ has no effect in the current period on $q k$.

If we try to change the closure to find the SDRORT value consistent with a given change in $q k$, we find it impossible. If we exogenize $q k(r)$ (for some region $r$ ) and endogenize $\operatorname{SDRORT}(r)$, we make the model singular, since we thereby make exogenous 
all variables in equation (10). The only natural way to exogenize $q k(r)$ is to swap it with $s q k(r)$, and that does not achieve the larger purpose, since it does not allow $q k(r)$ to determine $q c g d s(r)$ or SDRORT $(r)$.

Another one-way relation is that between the actual rate of return RORGROSS and the expected rate RORGEXP. According to the GTAP-Dyn theory, changes in RORGEXP cause changes in RORGROSS, yet rorga does not appear in the equation for rorge, equation (53),

$$
\begin{aligned}
& \operatorname{rorge}(r)=-\operatorname{RORGFLEX}(r)(q k(r)-100 . K H A T(r) . \text { time }) \\
& \text {-100.LAMBRORGE }(r) \text {.ERRRORG(r).time } \\
& +\operatorname{srorge}(r) \text {. }
\end{aligned}
$$

In a single-step simulation, indeed, rorga has no effect on rorge; in a multi-step simulation however, it affects ERRRORG at each data file update, and thereby affects rorge.

If you shock some exogenous variable so as to increase the actual rate of return - if for example you apply a positive shock to labor supply qo ("labor", $r$ ) - this has no effect on the expected rate rorge $(r)$ in a single-step simulation, but does affect it in a multi-step simulation. But if you want to find the labor supply change needed to achieve a given change in the expected rate of return, you find that you cannot exogenize rorge $(r)$ and endogenize qo "labor", $r$ ). To do so would create a singular system: the two-equation subsystem comprising the capital accumulation equation (10) and the expected rate of return equation (53) for region $r$ would contain only one endogenous variable, $q k(r)$. The only natural way to exogenize rorge $(r)$ is to endogenize srorge $(r)$, and this does not achieve the purpose of determining labor supply endogenously.

Since closure swaps do not work at all across these one-way relations, we evidently need some new computational machinery to let us target the naturally endogenous vari-

ables in them. It seems likely that the machinery needed to handle path dependencies (subsection 6.3) would handle this job also.

\subsection{Capital account volatility and the propensity to save}

GTAP-Dyn inherits from standard GTAP its specification of the regional household demand system, and, in particular, the treatment of saving. As in standard GTAP, there is a fixed average propensity to save; in other words, saving is a fixed proportion of income in each region.

One unwelcome implication of this is that the capital account, and net foreign liabil- 
ities, are highly volatile in GTAP-Dyn simulations. In the real world, for reasons that are poorly understood, saving and investment are highly correlated across countries, and international capital flows are much smaller and more stable than simple theory would suggest (Feldstein and Horioka, 1980). In GTAP-Dyn, we do not impose any such correlation, so relatively modest economic shocks can lead to unrealistically large international capital flows, and unrealistically large changes in regions' net foreign liabilities. Modifying this behavior is a promising area for future work on the GTAP-Dyn theoretical structure.

\section{Concluding remarks}

This paper presented a set of new equations added to the GTAP model in order to construct GTAP-Dyn, a dynamic AGE model of the world. The new theory offers a disequilibrium approach to modeling endogenously international capital mobility in a dynamic applied general equilibrium setting, and takes into account stock-flow dynamics and foreign asset income flows. The method can be especially attractive to policy modelers as it permits a recursive solution procedure, a feature that allows easy implementation of dynamics into any static AGE model without imposing limitations on the model's size.

Key to the proposed approach are investors' adaptive expectations about potential returns to capital. This type of expectations emphasizes errors in investors' assessment of potential returns to capital - such as those observed in the Asian financial crisis. It can also be shown that it ensures the convergence of the model towards a stable equilibrium and offers flexibility of tailoring the model to observed data.

Despite some limitations of GTAP-Dyn, such as the lack of equity-for-debt substitution, the absence of bilateral detail, and the lack of forward looking behavior, the model offers an unique and simple treatment of international capital mobility in a dynamic AGE context. It captures endogenously the economy-wide effects of capital and wealth accumulation, and the income effects of foreign property ownership.

\section{References}

Feldstein, M. and Horioka, C. (1980), "Domestic Saving and International Capital Flows," Economic Journal 90:358, pp. 314-29.

Gehlhar, M., and D. Gray, T.W. Hertel, K.M. Huff, E. Ianchovichina, B.J. McDonald, R. McDougall, M.E. Tsigas, and R. Wigle (1997), "Overview of the GTAP data 
base," in Hertel, T.W., (editor), Global Trade Analysis Modeling and Applications, Cambridge University Press, Chapter 3, pp. 74-124.

Harrison, W.J. and K.R. Pearson (1998), An Introduction to GEMPACK, GEMPACK Document No. GPD-1, 4th ed., Centre of Policy Studies and Impact Project, Monash University.

Hertel, T.W. (ed.) (1997), Global Trade Analysis Modeling and Applications, Cambridge University Press.

Hertel, T.W. and M.E. Tsigas (1997), "Structure of GTAP," in Hertel, T.W., (editor), Global Trade Analysis Modeling and Applications, Cambridge University Press, Chapter 2, pp. 13-73.

Huff, K. and Hertel, T.W. (1996), Decomposing Welfare Changes in GTAP, Technical Paper No. 5, Center for Global Trade Analysis, Purdue University.

Ianchovichina, E.I. (1998), International Capital Linkages: Theory and Application in a Dynamic Computable General Equilibrium Model, Ph.D. thesis, Department of Agricultural Economics, Purdue University.

Kapur, J.N. and H.K. Kesavan (1992), Entropy Optimization Principles with Applications, Academic Press, New York.

McDougall, R.A., ed., (1997), Global Trade, Assistance, and Protection: The GTAP 3 Data Base, Center for Global Trade Analysis, Purdue University.

McDougall, R.A. and A. Elbehri and T.P. Truong, eds (1998), Global Trade, Assistance, and Protection: The GTAP \& Data Base, Center for Global Trade Analysis, Purdue University. 


\section{A Tables}

Table 1: Investment Module

$$
\begin{aligned}
& \operatorname{DRORT}(r)=S D R O R T W+S D R O R T(r) \\
& R O R G T A R G(r) \cdot \operatorname{rorgt}(r)=\operatorname{DRORT}(r) \\
& \operatorname{rorge}(r)=-\operatorname{RORGFLEX}(r)[q k(r)-100 . \operatorname{KHAT}(r) . \text { time }] \\
& \text { - 100.LAMBRORGE }(r) \text {. ERRRORG }(r) \text {. time }+\operatorname{srorge}(r) \\
& \operatorname{erg} \_ \text {rorg }(r)=L A M B R O R G(r)[\operatorname{rorgt}(r)-\operatorname{rorge}(r)] \\
& D K H A T(r)=L A M B K H A T(r) \\
& {\left[R O R G F L E X(r)^{-1} \operatorname{rorga}(r)+q k(r)-100 . K H A T(r) . \text { time }\right]} \\
& \operatorname{erg} \_r o r g(r)=-R O R G F L E X(r)\{\operatorname{IKRATIO}(r)[q c g d s(r)-q k(r)]-D K H A T(r)\}
\end{aligned}
$$




\section{B Figures}

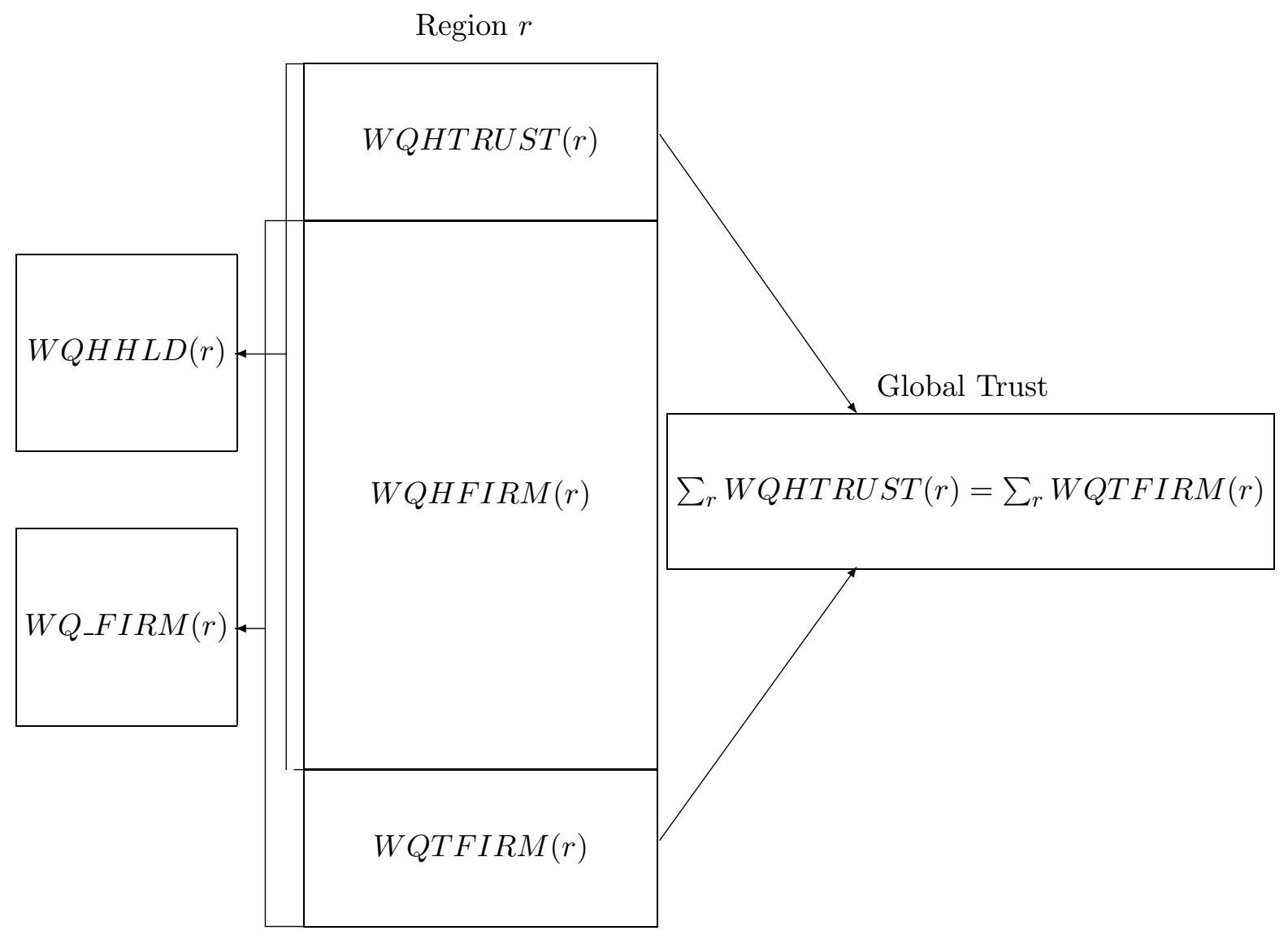

Figure 1: Wealth Linkages 


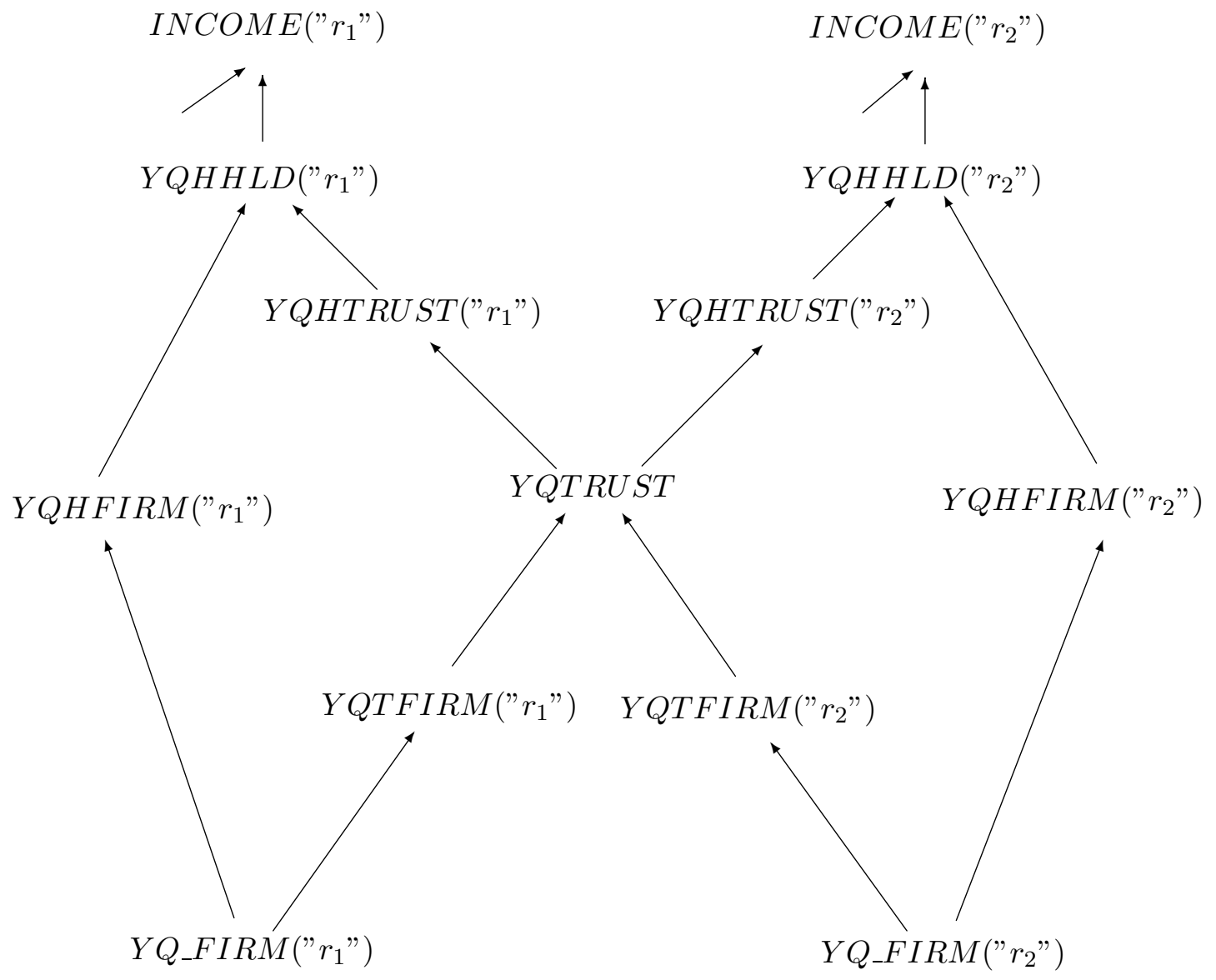

Figure 2: Income Linkages 


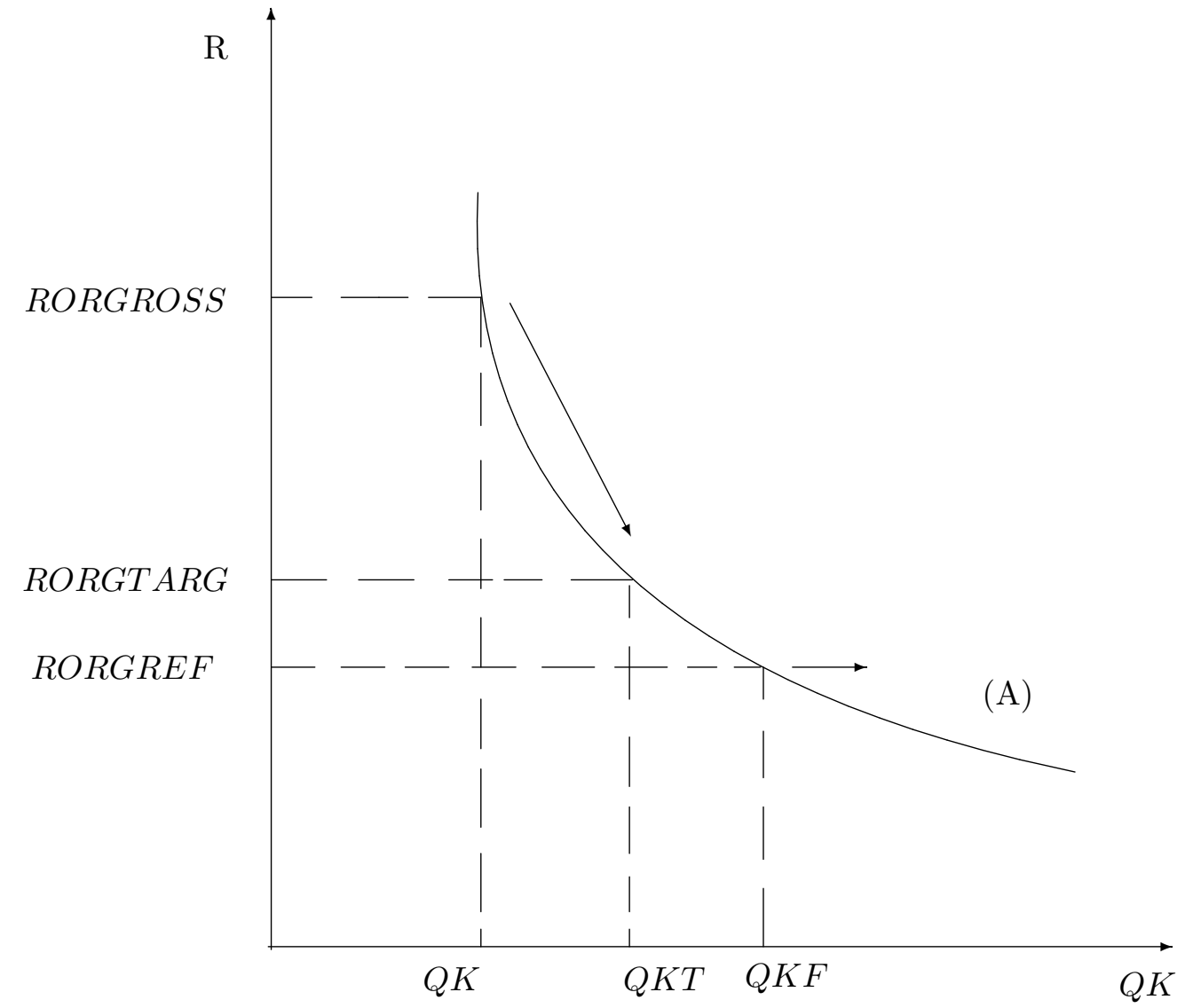

Figure 3: Actual Investment Schedule 


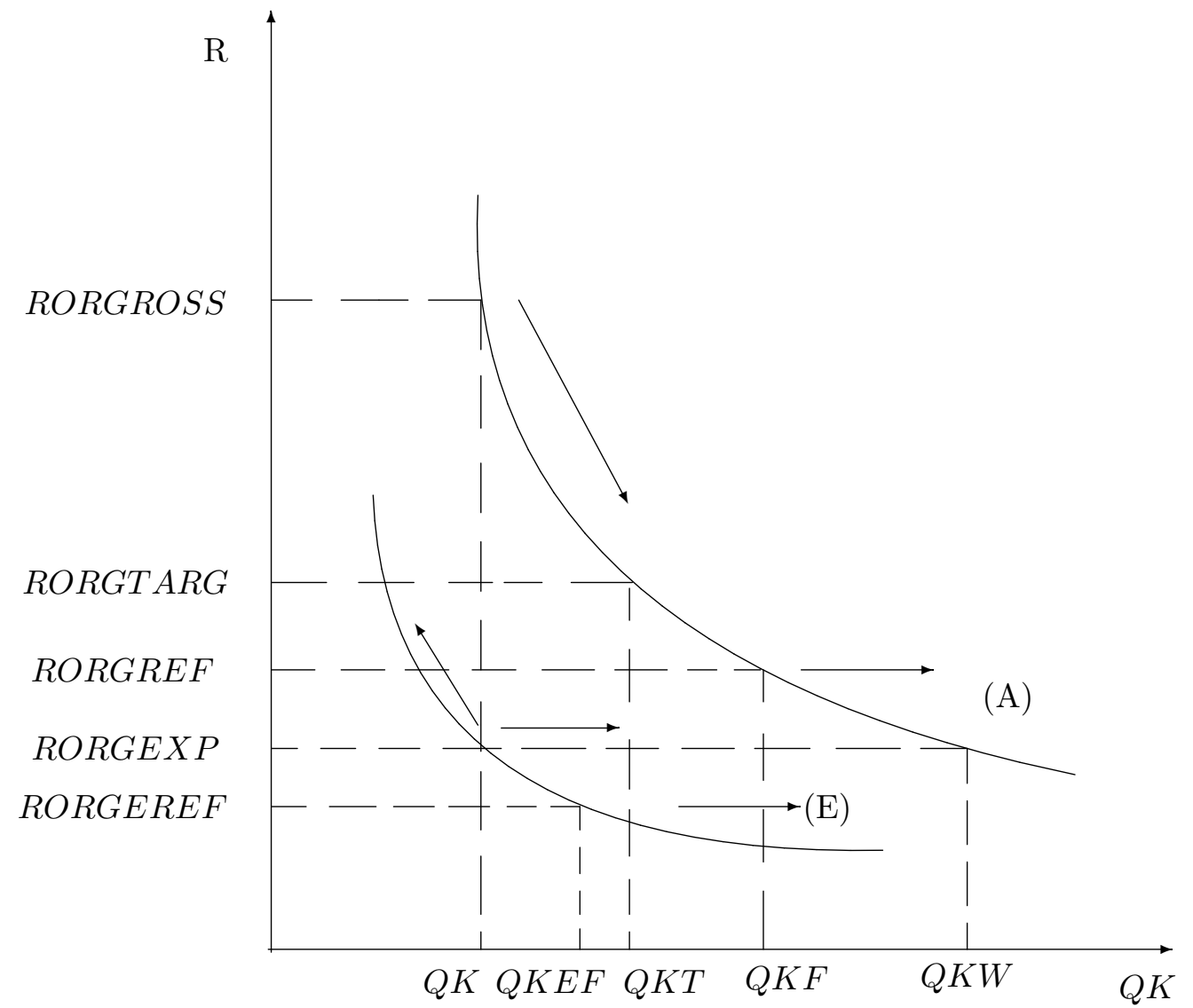

Figure 4: Actual and Expected Investment Schedules 


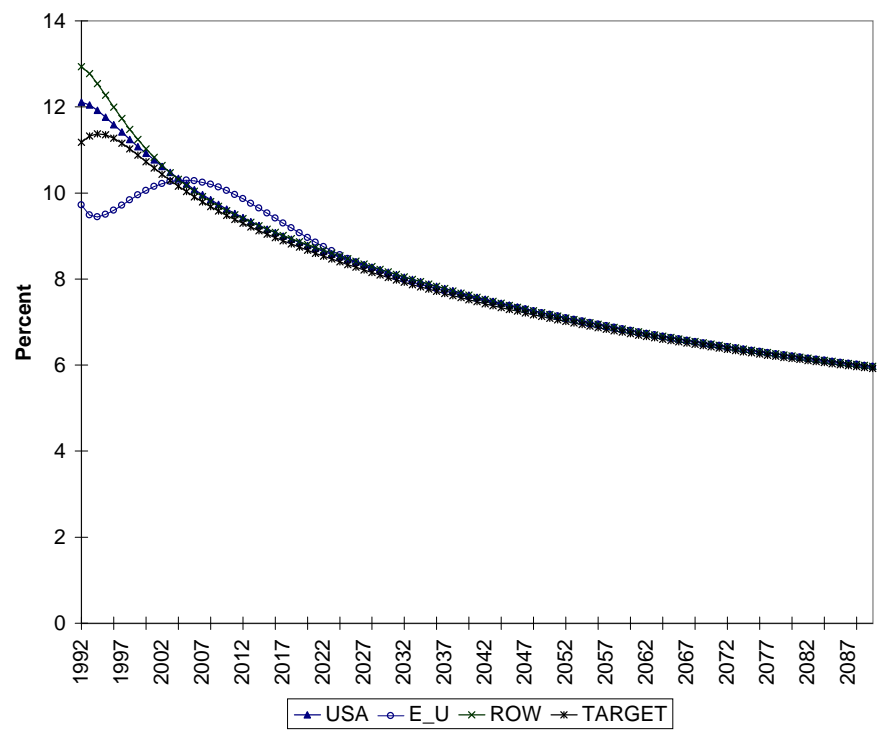

Figure 5: Actual and Target Rates of Return

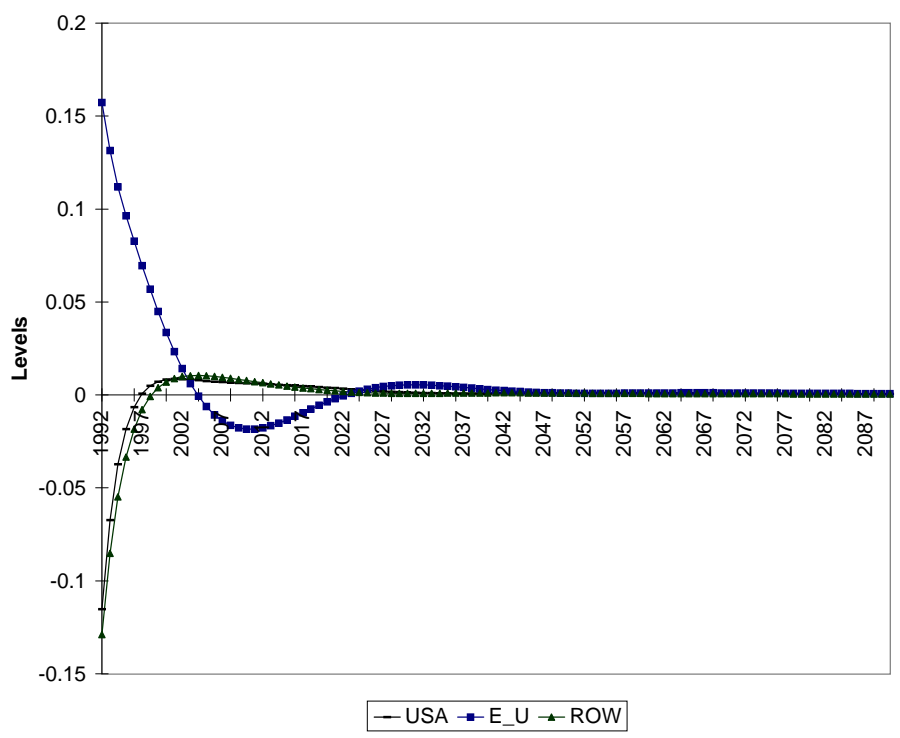

Figure 6: Errors in Expectations 


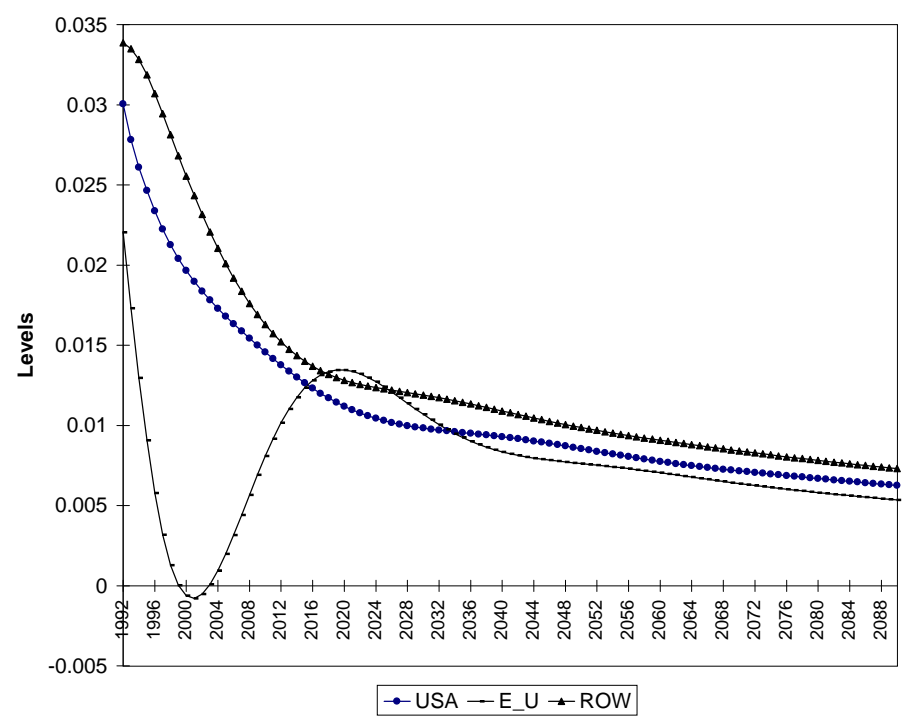

Figure 7: Normal Rate of Growth in Capital Stock, KHAT $(r)$

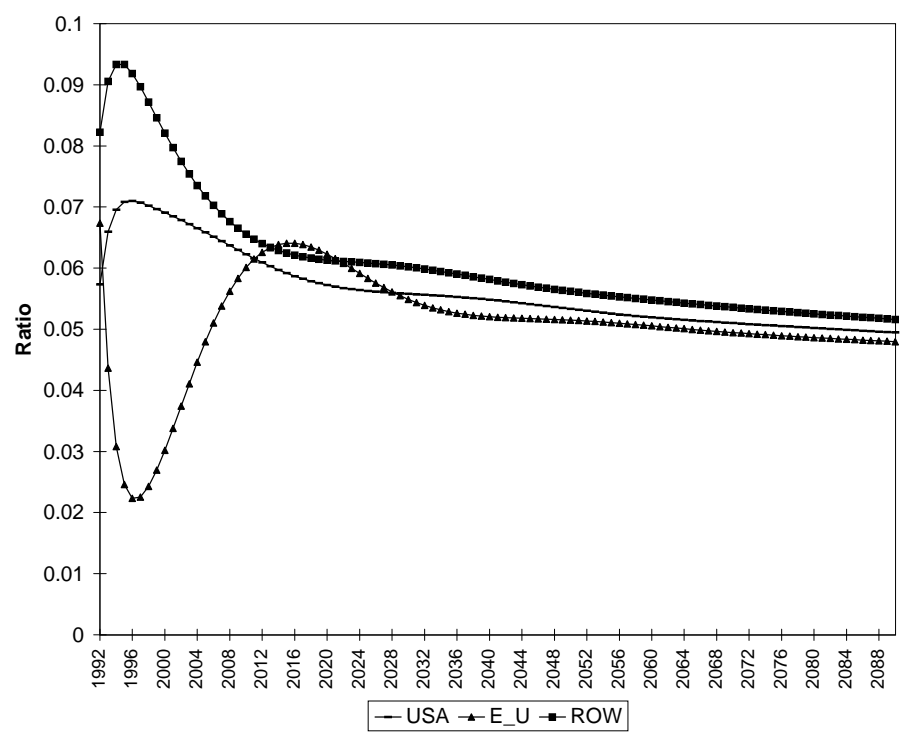

Figure 8: Investment-capital ratio 
C NOMENCLATURE

\section{Nomenclature}

BASE DATA

Value Flows

SAVE $(r) \quad$ Savings of regional household $r, \forall r$.

$\operatorname{VDEP}(r) \quad$ Value of capital depreciation in region $r, \forall r$.

$V K(r) \quad$ Value of capital stock in region $r, \forall r$.

$\operatorname{YQHFIRM}(r) \quad$ Income from equity paid to households $r$ by domestic firms, $\forall r$.

YQHTRUST $(r) \quad$ Income from equity paid to regional household $r$ by the trust, $\forall r$.

$\operatorname{YQTFIRM}(r) \quad$ Income from equity paid to the trust by domestic firms in $r$, $\forall r$.

Investment Data

KHAT $(r) \quad$ Normal rate of growth in the capital stock in region $r, \forall r$.

RORGEXP(r) Expected rate of return (gross) in region $r, \forall r$.

RORGTARG(r) Target rate of return (gross) in region $r, \forall r$.

PREFERENCE AND MOBILITY PARAMETERS

$L A M B K H A T(r) \quad$ Parameter determining the speed of adjustment in the normal rate of growth $K H A T(r)$ in region $r, \forall r$.

$\operatorname{LAMBRORG}(r) \quad$ Parameter determining the speed of adjustment in the rate of return in region $r, \forall r$.

LAMBRORGE $(r)$ Parameter determining the speed with which errors in expectation are eliminated in region $r, \forall r$. 
$R I G W Q_{-} F(r) \quad$ Parameter determining the rigidity of source of funding by both the trust and the regional household for firms in region $r, \forall r$.

RIGWQH $(r) \quad$ Parameter determining the rigidity of allocation of total wealth in equity owned by the regional household $r$ and invested in both the trust and the domestic firms, $\forall r$.

RORGFLEX $(r) \quad$ Elasticity of the rate of return with respect to capital stock in region $r, \forall r$. 
C NOMENCLATURE

DERIVATIVES OF THE BASE DATA

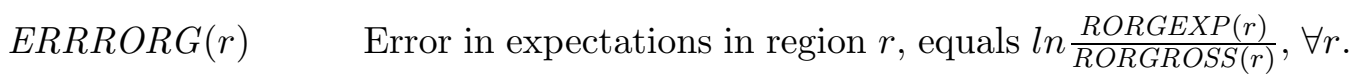

$\operatorname{IKRATIO}(r)$ Investment-capital ratio in region $r$, equals $R E G I N V(r) / V K(r), \forall r \in R E G$.

NETINV $(r) \quad$ Net investment in region $r$, equals $R E G I N V(r)-V D E P(r)$, $\forall r$.

REGINV(r) Gross investment in region $r$, equals $V O A(" c g d s ", r), \forall r$.

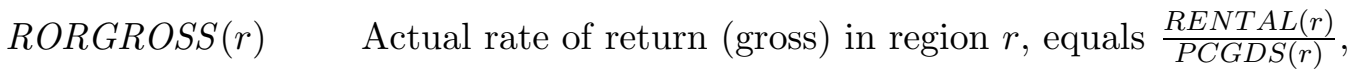
$\forall r$.

$V O A(i, r) \quad$ Value of nonsavings commodity $i$ output supplied in region $r$ and evaluated at agents' prices, $\forall i$ and $\forall r$.

$W Q_{-} F I R M(r) \quad$ Total wealth in equity invested by the domestic household and by the trust in regional firms in region $r$, equals $V K(r)$ or $\operatorname{WQHFIRM}(r)+\operatorname{WQTFIRM}(r), \forall r$.

WQ_TRUST Total wealth in equity invested by all regional households $r$ in the global trust, equals $\sum_{r} W Q H T R U S T(r)$.

$\operatorname{WQHFIRM}(r) \quad$ Wealth in equity owned by the regional household $r$ and invested in domestic firms, equals $\frac{\operatorname{YQHFIRM}(r)}{\operatorname{YQ} Q_{-} \operatorname{FIRM}(r)} V K(r), \forall r$.

$W Q H H L D(r) \quad$ Total wealth in equity owned by regional household $r$ and invested in both the trust and domestic firms, equals $W Q H F I R M(r)+W Q H T R U S T(r), \forall r$.

WQHTRUST $(r) \quad$ Total wealth in equity owned by the regional household in $r$ and invested in the trust, equals $\frac{Y Q H T R U S T(r)}{Y Q_{-} T R U S T} W Q_{-} T R U S T$, $\forall r$.

$W Q T \_F I R M S H R(r)$ Share of region $r$ equities in total assets of the global trust, equals $\frac{W Q T F I R M(r)}{W Q T R U S T}, \forall r$ 
$\operatorname{WQTFIRM}(r) \quad$ Wealth in equity owned by the global trust and invested in regional firms in region $r$, equals $\frac{\operatorname{YQTFIRM}(r)}{\operatorname{YQ} Q_{-} \operatorname{IRM}(r)} V K(r), \forall r$

WQTRUST Total wealth in equity owned by the trust and invested in regional firms across all regions, equals $\sum_{r} W Q T F I R M(r)$.

$Y Q_{-} F I R M(r) \quad$ Total income on equity paid to both the trust and the regional household by regional firms in region $r$, equals $V O A($ "capital", $r)-\operatorname{VDEP}(r), \forall r$.

$Y Q H H L D(r) \quad$ Total income from equity paid to the regional household $r$ by both the domestic firms and by the trust, equals $Y Q H F I R M(r)+Y Q H T R U S T(r), \forall r$.

YQTRUST Total income from equity paid to the trust by all regional firms, equals $\sum_{r} Y Q T F I R M(r)$. 

VARIABLES
Quantity Variables
QCGDS $(r) \quad$ Capital goods in region $r, \forall r$.
$Q K(r) \quad$ Capital stock in region $r, \forall r$.
$Q K O(h, r) \quad$ Supply of input (output) $h$ in region $r, \forall r$.

Price Variables

$\operatorname{pcgds}(r) \quad$ Percentage change in the price of investment goods in region $r, \forall r$.

pqtrust Percentage change in the price of equity invested in the trust.

$p s(h, r) \quad$ Percentage change in the supply price of input (output) $h$ in region $r, \forall r$.

rental $(r) \quad$ Percentage change in the rental rate on capital stock in region $r, \forall r$.

Investment Variables

DKHAT $(r) \quad$ Change in the normal rate of growth in the capital stock $K H A T(r)$ in region $r, \forall r$.

$\operatorname{DRORT}(r) \quad$ Absolute change in the target rate of return $R O R G T A R G(r)$ in region $r, \forall r$.

erg_rorg $(r) \quad$ Change in the expected rate of growth in the rate of return $R O R G R O S S(r)$ in region $r, \forall r$.

rorga $(r) \quad$ Percentage change in the actual (gross) rate of return in

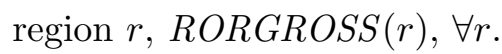

rorge $(r) \quad$ Percentage change in the expected (gross) rate of return in region $r, R O R G E X P(r), \forall r$. 
$\operatorname{rorgt}(r)$

time

Wealth Variables

$w q_{-} f(r)$

$w q_{-} t$

$w q h(r)$

$w q h f(r)$

$w q h t(r)$

$w q t$

$w q t f(r)$

Income Variables

$y q_{-} f(r)$

$y q h(r)$
Percentage change in the target (gross) rate of return in region $r, R O R G T A R G(r), \forall r$.

Variable measuring the length of the simulation period.

Percentage change in total wealth in equity invested by both the regional household and the trust in the regional firms in $r, W Q_{-} F I R M(r), \forall r$.

Percentage change in total wealth in equity invested by all regional households in the trust, WQ-TRUST.

Percentage change in total wealth in equity owned by the regional household $r$ and invested in both the domestic firms and the trust, $W Q H H L D(r), \forall r$.

Percentage change in wealth in equity owned by the regional household $r$ and invested in domestic firms, WQHFIRM $(r)$, $\forall r$.

Percentage change in wealth in equity owned by the regional household $r$ and invested in the trust, WQHTRUST( $r), \forall r$.

Percentage change in the wealth in equity owned by the trust, WQTRUST.

Percentage change in wealth in equity owned by the trust and invested in the regional firms in $r, \operatorname{WQTFIRM}(r), \forall r$.

Percentage change in total income from equity paid to the regional household $r$ and the trust by regional firm $r$, $Y Q_{-} F I R M(r), \forall r$.

Percentage change in total income on equity paid to regional households $r$ by both domestic firms and the trust, $Y Q H H L D(r), \forall r$. 


$$
\begin{array}{ll}
\text { yqhf }(r) & \begin{array}{l}
\text { Percentage change in income from equity paid to the regional } \\
\text { households } r \text { by domestic firms in } r, Y R F E Q Y(r), \forall r .
\end{array} \\
y q h t(r) & \begin{array}{l}
\text { Percentage change in income from equity paid to the region } \\
\text { household } r \text { by the trust, } Y Q H T R U S T(r), \forall r .
\end{array} \\
y q t & \text { Percentage change in total income from equity paid to the } \\
& \text { trust by all regional firms, } Y Q T R U S T . \\
y q t f(r) & \text { Percentage change in income from equity paid to the global } \\
& \text { trust by domestic firms in } r, Y T F E Q Y(r), \forall r .
\end{array}
$$

Shift and Slack Variables

$\operatorname{SDRORT}(r) \quad$ Absolute change in the shift variable specific to region $r$ in the target rate of return equation (41), $\forall r$.

SDRORTW Absolute change in the region-generic shift variable in the target rate of return equation (41).

sqcgdsreg $(r) \quad$ Percentage change in the shift variable specific to region $r$ in the equation (57) determining investment in an alternative way, $\forall r$.

sqcgdsworld Percentage change in the region-generic shift variable in the equation (57) determining investment in an alternative way.

$s q k(r)$ Percentage change in the shift variable specific to region $r$ in the capital accumulation equation (10), $\forall r$.

sqkworld Percentage change in the region-generic shift variable in the capital accumulation equation (10).

$\operatorname{srorge}(r)$ Percentage change in the exogenous shift variable in expected gross rate of return in region $r$ in equation (53), $\forall r$.

wtrustslack Percentage change in the slack variable in the world foreign equity balance equation (28). 
$x w q_{-} f(r) \quad$ Absolute change in the Lagrange multiplier for the household wealth constraint (20) in region $r, \forall r$.

$x w q h(r) \quad$ Absolute change in the Lagrange multiplier for the firm value constraint (21) in region $r, \forall r$. 